Author accepted version. Final publication as:

Davidson, M.J., Gaskin, S.J. \& Wood, I.R. (2002) A study of a buoyant axisymmetric jet in a small co-flow, Journal of Hydraulics Research, 40(4), pp 477- 489. doi.org/10.1080/00221680209499890

\title{
A study of a buoyant axisymmetric jet in a small co-flow
}

M. J. Davidson, Department of Civil Engineering, Hong Kong University of Science and Technology, Clearwater Bay, Hong Kong

S. Gaskin, Department of Civil Engineering and Applied Mechanics, McGill University, Montreal, Canada.

I. R. Wood, Department of Civil Engineering, University of Canterbury, Private Bag 4800, New Zealand

\begin{abstract}
This paper deals with measurements of and an integral model for a buoyant axisymmetric jet in a very small coflow. The integral model is based on the insights gained from the measurements presented here and other recent experiments, which suggest that the turbulent flow is simply advected and the entrainment is that normal for a jet or plume in a still ambient fluid. General equations for the turbulent flow trajectories are also developed. The predictions of the theory are verified for the no cross-flow case and the cases where the jet or plume is ejected vertically or horizontally into a very small cross-flow.
\end{abstract}

The results of experiments in which a buoyant jet is released in the same direction as the horizontal ambient flow, show that outside the turbulent region the entrainment velocities can be represented with uniform flow and the appropriate sink. Direct measurement of the strength of the sink allows the transition from weakly- to stronglyadvected behaviour to be determined. The departure of the trajectory measurements from the theory also provides information about the transition. The transition location is then compared with recent measurements in which the jets and plumes are ejected vertically into a very small cross-flow. 
Author accepted version. Final publication as:

Davidson, M.J., Gaskin, S.J. \& Wood, I.R. (2002) A study of a buoyant axisymmetric jet in a small co-flow, Journal of Hydraulics Research, 40(4), pp 477- 489. doi.org/10.1080/00221680209499890

\section{Introduction}

The behaviour of single axisymmetric discharges has been studied extensively in the past, because of their importance in assessing the environmental impact of pollutants released into the ocean and the atmosphere. Previous experimental investigations into these flows, which have been conducted mostly with relatively high ratios of ambient velocity to jet velocity, have shown that the flow is initially jet-like. After some distance the buoyancy generated vertical momentum governs and the effluent behaviour resembles a plume. Finally the entrained ambient momentum governs and the plume becomes almost horizontal, behaving like an advected thermal (Scorer 1958). These experiments are appropriate for discharges in the atmosphere and for some ocean outfalls discharges. However for many cases the initial velocity from an outfall is of the order of $10 \mathrm{~m} / \mathrm{s}$ whereas the ambient velocity is of the order of $10 \mathrm{~mm} / \mathrm{s}$, hence the ratio of the ambient velocity to the initial jet velocity is very small. This implies that only the jet and plume regimes exist as the effluent rises to the surface.

The importance of the discharges in relatively weak currents is the motivation for this study. In addition recent advances in optical measurement techniques, namely the development of laser induced fluorescence (LIF) and particle image velocimetry (PIV) systems, have enabled these flows to be studied in a degree of detail not possible previously. Davidson and Pun (1999) and Pun and Davidson (1999) investigated the behaviour of vertical jets and plumes released in a weak crossflow. They employed a LIF system to make detailed measurements of the concentration field in these flows. Among other things they were able to show that the spatial distributions of the tracer temporal mean and fluctuation statistics resemble those from a equivalent discharge released into a still ambient fluid.

In this paper we begin by reviewing the behaviour of jets and plumes with particular reference to the entrainment velocities that are established outside the turbulent flow. For a very small co-flow this information is used to develop the integral model where it is assumed that the only significant effect of the ambient current is to advect the effluent. We then employ a PIV system to study the irrotational velocity field outside of the turbulent flow. A towing tank facility is used to simulate the release of a buoyant jet in a relatively weak current, which is flowing in the same 
Author accepted version. Final publication as:

Davidson, M.J., Gaskin, S.J. \& Wood, I.R. (2002) A study of a buoyant axisymmetric jet in a small co-flow, Journal of Hydraulics Research, 40(4), pp 477- 489. doi.org/10.1080/00221680209499890

direction as the initial discharge. Measurements are made outside the turbulent buoyant flow and they show that the irrotational flow field can be represented with a uniform flow and an appropriate sink. Further the direct measurement of the strength of the sink for these experiments show that for a very small cross-flow the sink strength is the same as that in a still ambient fluid. A more detailed description of these experiments is given in Gaskin (1995). Predictions from the integral model are then compared with available experimental data and are shown to provide reliable predictions for weakly-advected flows.

Additional experiments for relatively large cross-flows were also conducted and these show that the sink strength increases in the advected thermal region. This information provides the basis for developing local conditions for the transition from weakly to strongly behaviour. The location of the transition from plume like to advected thermal like behaviour is normally determined from a length-scale analysis (Pun and Davidson 1999 for example). The local conditions for vertically discharged and horizontally discharged buoyant flows are shown to be different.

\section{The Equations With No Cross-flow}

It is appropriate to discuss initially the case when there is no co-flow and the flow is vertical (Figure 1). Morton Taylor and Turner (1956) used the boundary layer assumption to show that the average profiles are self similar and that there was an average entrainment into the jet-like flow, that was proportional the mean centre-line velocity. They introduced the continuity equation and proceeded, using an integral method, to the solution.

Discharges that are driven by small density differences may resemble a jet, but at any distance the buoyancy causes its momentum flux to increase and its rate of entrainment is different from that of a jet. Indeed the recent measurements of Papantoniou and List (1989) show that the entrainment mechanism is the same in both jets and plumes and is dominated by almost periodic large scale motions which engulf the ambient fluid. The unmixed fluid is transported well into the turbulent fluid and mixed by the action of small eddies. However plume-like flows oscillate more than jets and measurements of intermittency, the percentage of time a probe is in the turbulent flow, show that during entrainment the penetration of tongues of ambient fluid from outside to the centre-line is much 
Author accepted version. Final publication as:

Davidson, M.J., Gaskin, S.J. \& Wood, I.R. (2002) A study of a buoyant axisymmetric jet in a small co-flow, Journal of Hydraulics Research, 40(4), pp 477- 489. doi.org/10.1080/00221680209499890

greater in plumes than jets. This allows the flux of volume to increase more rapidly in the plume case and shows that standard deviation of any tracer is very much greater in the plume flow. It also leads to the average entrainment constant for the jet-like flow being less than in a plume-like flow.

Abraham (1963) noted that the rate of expansion of a buoyant flow was independent of the type of flow (jet-like or plume-like) and with this alternative assumption proceeded to the solution. List and Imberger (1973) and Jirka and Harleman (1979) were able to relate the two assumptions and derive the entrainment constants for the jet and the plume.

The solutions discussed above are for average velocities and concentrations inside the narrow buoyant jet region. Outside this region the flow is irrotational and its form depends upon the boundary conditions and whether the flow is dominated by the initial momentum or the buoyancy generated momentum (Taylor 1958, Kotsovinos 1975).

Numerous experiments (List in Fischer et al 1979) have shown that the time averaged velocity distribution of the buoyant jet is self-preserving and in infinite surroundings can be approximated by

$$
\bar{u}=U e^{-(r / b)^{2}}
$$

Where $\bar{u}$ is the temporal average of the buoyant jet velocity $(u)$ at radius $r, U$ is the time averaged centre-line velocity and $b$ is the radius when $\bar{u} / U$ is $1 / e$.

Similarly for the density, the distribution can be approximated by

$$
\Delta_{l}=\Delta e^{-(r / \lambda b)^{2}}
$$

Where $\Delta_{l}$ is the local time averaged buoyancy $(\Delta \rho g / \rho)$ and $\Delta$ is the time-averaged buoyancy on the centre-line. The symbol $\lambda$ represents the difference in the spread of the velocity and the buoyancy. It is assumed to have a value of 1.07 (Papanicolaou \& List, 1988). 
Author accepted version. Final publication as:

Davidson, M.J., Gaskin, S.J. \& Wood, I.R. (2002) A study of a buoyant axisymmetric jet in a small co-flow, Journal of Hydraulics Research, 40(4), pp 477- 489. doi.org/10.1080/00221680209499890

At some distance $(s)$ from the zone of flow establishment the continuity equation, as written by Morton et al (1956) and others, is

$$
\frac{d}{d s} \int_{0}^{\infty} \bar{u} 2 \pi r d r=2 \pi \alpha U b
$$

It is traditional to use the entrainment velocity at a radius of $b$ and this velocity is $\alpha U$ where $\alpha$ is the entrainment coefficient. It should be noted that the influx of volume is intermittent and is associated with the passage of the periodic large eddies in the jet or plume. Away from this intermittency the flow in the external field outside the jet can be modelled by a distribution of sinks along the axis (Taylor 1958, Turner 1973). For a pure jet issuing from a horizontal wall Taylor showed that the strength of the sink is constant and the streamlines are horizontal. For a pure plume this is not the case in that the strength of the sink is not constant (it varies in proportion to $s^{2 / 3}$ ) and the streamlines are not strictly horizontal. However the experimental results of Rouse et al (1952) show that the departure from horizontal streamlines is not great. For this case if the entrainment flow streamlines are almost horizontal, then with a control volume of radius $r_{l}$ we can deduce the average radial velocity $\bar{u}_{r_{l}}$.

$$
\frac{d}{d s}\left\{\int_{0}^{r_{l}} \bar{u} 2 \pi r d r\right\}=\frac{d}{d s}\left\{U b^{2} \int_{0}^{r_{I} / b} \frac{\bar{u}}{U} 2 \pi \frac{r}{b} d\left(\frac{r}{b}\right)\right\}=\bar{u}_{r_{I}} 2 \pi r_{1}
$$

Noting that $b$ is a function of $s$, equation 4 can be written as

$$
\begin{aligned}
& {\left[\int_{0}^{r_{1} / b} \frac{\bar{u}}{U} 2 \pi \frac{r}{b} d\left(\frac{r}{b}\right)\right] \frac{d}{d s}\left\{U b^{2}\right\}+U b^{2} \frac{d}{d s}\left\{\int_{0}^{r_{1} / b} \frac{\bar{u}}{U} 2 \pi \frac{r}{b} d\left(\frac{r}{b}\right)\right\}} \\
& =\pi\left[1-e^{-(r / b)^{2}}\right] \frac{d}{d s}\left\{U b^{2}\right\}-U b^{2} e^{-(r / b)^{2}} 2 \pi \frac{r_{l}^{2}}{b^{3}} \frac{d b}{d s} \\
& =\bar{u}_{r_{l}} 2 \pi r_{1}
\end{aligned}
$$

and dropping the subscript 1 we get for all $r$

$$
\frac{\bar{u}_{r}}{\alpha U}=\frac{b}{r}-\frac{b}{r} e^{-(r / b)^{2}}-\frac{1}{\alpha} \frac{d b}{d s} \frac{r}{b} e^{-(r / b)^{2}}
$$

In the far field, outside the turbulent flow, the radial velocity is given by the average entrainment velocity, which is the first term in equation (6). However, once inside the turbulent flow, the average entrainment velocity 
Author accepted version. Final publication as:

Davidson, M.J., Gaskin, S.J. \& Wood, I.R. (2002) A study of a buoyant axisymmetric jet in a small co-flow, Journal of Hydraulics Research, 40(4), pp 477- 489. doi.org/10.1080/00221680209499890

reduces towards zero as $r$ reduces and hence the presence of the second term in equation (6). Within the turbulent flow there is an additional radial velocity due to the mean expansion of the flow and this is represented by the third term in equation (6). For a jet the measurements in the classic paper of Albertson et al. (1948) are shown in Figure 2a. In this study the total velocity and its angle were measured and the radial velocities were constructed using the continuity equation and the measured component along the axis of the jet. The results are in qualitative agreement with the deductions for an axial Gaussian velocity distribution. The theoretical dimensionless radial velocity, based on the Gaussian distribution, is illustrated in Figure $2 b$ for both the jet and the plume. This gives a two-dimensional streamline function for the radial flow of approximately

$$
\psi=\frac{d \bar{q} / d s}{2 \pi}\left[1-e^{-(r / b)^{2}}-\frac{1}{\alpha} \frac{d b}{d s}\left(\frac{r}{b}\right)^{2} e^{-(r / b)^{2}}\right] \operatorname{Tan}^{-1}\left(\frac{y}{x}\right)
$$

Where $\bar{q}$ is the temporal average of the volume flux of the flow and $x$ and $y$ are the Cartesian coordinates.

\section{The Equations With a Very Small Cross-flow in Infinite Surroundings}

In the established flow it will be assumed that the flow is simply advected as in Figure 3, where the subscript $e$ indicates the excess velocity. For the case when the ratio of the cross-flow velocity $\left(U_{\infty}\right)$ to maximum jet or plume velocity is very small, we assume that the periodic eddy distribution is unchanged, but is advected with a velocity of $U_{\infty}$. This implies the average velocity distribution will still be Gaussian. However in the region close to the source from which the buoyant jet is ejected, there will be a length of flow establishment in which the pipe velocity distribution is still evident. This occurs until the boundary layer formed outside of the pipe merges to form the Gaussian flow.

The density of a jet is the same as that of the ambient fluid and thus there can be no wake. Similarly for a plume the density difference is so small that any wake can be ignored. Therefore the flow outside the turbulent region can be approximated by the superposition of a distribution of sinks, due to the entrainment into the turbulent region, and the uniform flow (this is verified in the subsequent experiments). 
Author accepted version. Final publication as:

Davidson, M.J., Gaskin, S.J. \& Wood, I.R. (2002) A study of a buoyant axisymmetric jet in a small co-flow, Journal of Hydraulics Research, 40(4), pp 477- 489. doi.org/10.1080/00221680209499890

The entrainment into any jet in a flowing ambient fluid is due to the excess velocity. The entrainment into the turbulent region consists of that due to the Gaussian distribution and that due to the vortex distribution set up by the cross-flow. With the very small cross-flow the entrainment due to the vortex pair is ignored.

It is convenient to derive these equations with the plume between two solid vertical plates, a distance $b_{d}$ apart, and aligned in the direction of the ambient flow, as illustrated in figure 4 . For the case when $b_{d}$ is very much greater than the typical plume dimension the flow remains axisymmetric. This is typical of the situation found in a flume or towing tank experiment. The flow into the control volume is then given by the change in volume flux of the turbulent flow:

$$
\frac{d q}{d s}=\frac{d}{d s} \int_{0}^{R}\left(u_{e}+U_{\infty} \cos \theta\right) 2 \pi r d r
$$

where $R$ is the radius of the turbulent flow. As the turbulent structure is essentially the same as that of a discharge in a still ambient fluid, the excess velocity drives the flow into the control volume and hence the average of this flow can also be determined from:

$$
\frac{d \bar{q}}{d s}=2 \pi b \alpha U_{e}
$$

Using the control volume in Figure 4 and defining the pressure in the plume as $p$ and the pressure on the upstream $(\mathrm{A}, \mathrm{A})$ and downstream $(\mathrm{B}, \mathrm{B})$ faces respectively as $p_{a}$ and $p_{b}$, the horizontal momentum equation is

$$
\begin{gathered}
\frac{p_{a}}{\rho} b_{d} \sin \theta-\frac{p_{b}}{\rho} b_{d} \sin \theta= \\
+\frac{d}{d s} \int_{0}^{R}\left(u_{e}+U_{\infty} \cos \theta\right)\left(U_{\infty}+u_{e} \cos \theta\right) 2 \pi r d r-\frac{d}{d s} \int_{0}^{R} \frac{p}{\rho} \sin \theta 2 \pi r d r \\
+b_{d}\left(-\frac{d q}{d s} \frac{1}{2 b_{d}}+U_{\infty} \sin \theta\right)\left(-\frac{d q}{d s} \frac{1}{2 b_{d}} \sin \theta+U_{\infty}\right) \\
-b_{d}\left(+\frac{d q}{d s} \frac{1}{2 b_{d}}+U_{\infty} \sin \theta\right)\left(+\frac{d q}{d s} \frac{1}{2 b_{d}} \sin \theta+U_{\infty}\right)
\end{gathered}
$$

or 
Author accepted version. Final publication as:

Davidson, M.J., Gaskin, S.J. \& Wood, I.R. (2002) A study of a buoyant axisymmetric jet in a small co-flow, Journal of Hydraulics Research, 40(4), pp 477- 489. doi.org/10.1080/00221680209499890

$$
\begin{gathered}
-\frac{d}{d s} \int_{0}^{R}\left(u_{e}+U_{\infty} \cos \theta\right)\left(U_{\infty}+u_{e} \cos \theta\right) 2 \pi r d r+\frac{d}{d s} \int_{0}^{R} \frac{p}{\rho} \sin \theta 2 \pi r d r \\
=\frac{p_{b}}{\rho} b_{d} \sin \theta-\frac{p_{a}}{\rho} b_{d} \sin \theta \\
-U_{\infty} \frac{d q}{d s}\left(1+\sin ^{2} \theta\right)
\end{gathered}
$$

$U_{\infty}$ times the continuity equation is

$$
\frac{d}{d s} \int_{0}^{R} U_{\infty}\left(u_{e}+U_{\infty} \cos \theta\right) 2 \pi r d r=\frac{d q}{d s} U_{\infty}
$$

adding equation (12) to equation (11) gives

$$
\begin{gathered}
-\frac{d}{d s} \int_{0}^{R}\left(u_{e}+U_{\infty} \cos \theta\right)_{u_{e}} \cos \theta 2 \pi r d r+\frac{d}{d s} \int_{0}^{R} \frac{p}{\rho} \sin \theta 2 \pi r d r \\
=\left(\frac{p_{b}}{\rho} b_{d}-\frac{p_{a}}{\rho} b_{d}\right) \sin \theta \\
-U_{\infty} \frac{d q}{d s} \sin ^{2} \theta
\end{gathered}
$$

In the irrotational region the velocity has components perpendicular and parallel to the surface at AA (figure 4) and these are

$$
\begin{gathered}
u=\frac{d q}{d s} \frac{1}{2 b_{d}}+U_{\infty} \sin \theta \\
v=-U_{\infty} \cos \theta
\end{gathered}
$$

Similarly at BB the velocity components are

$$
\begin{gathered}
u=-\frac{d q}{d s} \frac{1}{2 b_{d}}+U_{\infty} \sin \theta \\
v=-U_{\infty} \cos \theta
\end{gathered}
$$

Now the Bernoulli equation gives

$$
\left(\frac{p_{b}}{\rho} b_{d}-\frac{p_{a}}{\rho} b_{d}\right)=\frac{1}{2}\left(V_{a}^{2}-V_{b}^{2}\right) b_{d}=\frac{d q}{d s} U_{\infty} \sin \theta
$$

Thus the end pressure and the entrained momentum terms cancel and the horizontal momentum equation simplifies to 
Author accepted version. Final publication as:

Davidson, M.J., Gaskin, S.J. \& Wood, I.R. (2002) A study of a buoyant axisymmetric jet in a small co-flow, Journal of Hydraulics Research, 40(4), pp 477- 489. doi.org/10.1080/00221680209499890

$$
\frac{d}{d s} \int_{0}^{R}\left(u_{e}+U_{\infty} \cos \theta\right) u_{e} \cos \theta 2 \pi r d r-\frac{d}{d s} \int_{0}^{R} \frac{p}{\rho} \sin \theta 2 \pi r d r=0
$$

In the same way the flux of vertical momentum equation becomes

$$
\begin{aligned}
\frac{d}{d s} \int_{0}^{R}\left(u_{e}+U_{\infty} \cos \theta\right) & u_{e} \sin \theta 2 \pi r d r-\frac{d}{d s} \int_{0}^{R} \frac{p}{\rho} \cos \theta 2 \pi r d r \\
& =\int_{0}^{R} \Delta 2 \pi r d r
\end{aligned}
$$

The flux of buoyancy is

$$
\int_{0}^{R}\left(u_{e}+U_{\infty} \cos \theta\right) \Delta 2 \pi r d r=q_{\Delta o}
$$

It is important to note (as expected) that there is no drag in the equations and the bending of the flow comes from the buoyancy and the entrained momentum flux.

Defining $\eta$ as $r / b$ and assuming that for very small cross-flow velocities the shapes of the excess velocity, the turbulent properties $\left(u_{e}^{\prime}, v^{\prime}\right.$ and $\left.w^{\prime}\right)$, the buoyancy distribution $(\Delta)$ and the buoyancy fluctuations $\left(\Delta^{\prime}\right)$ do not change, we can calculate the shape functions. Hussien et al (1994) defined $u_{e} / U_{e}=F(\eta), u_{e}^{\prime} / U_{e}=f(\eta), v^{\prime} / U_{e}=h(\eta)$ and $w^{\prime} / U_{e}=i(\eta)$ and shows, for a vertical jet with no co-flow, that the terms on the left hand side of equation (18) including the pressure term can be written as

$$
\begin{gathered}
\int_{0}^{\infty}\left\{F(\eta)^{2}+f(\eta)^{2}-\frac{1}{2}\left[h(\eta)^{2}+i(\eta)^{2}\right]\right\} 2 \pi \eta d \eta \frac{d}{d s}\left(U_{e}^{2} b^{2}\right) \\
=I_{m} \frac{d}{d s}\left(U_{e}^{2} b^{2}\right)
\end{gathered}
$$

Note the excess velocity distribution is integrated to infinity to be consistent with the Gaussian assumption.

The mean flow terms can be integrated to yield $\pi / 2$ and Hussien's experimental data suggests that the nondimensional turbulent terms are approximately $10 \%$ of the total flux. Thus we will adopt a value for the shape function $I_{m}$ of 1.7. The shape function for the volume flux is 
Author accepted version. Final publication as:

Davidson, M.J., Gaskin, S.J. \& Wood, I.R. (2002) A study of a buoyant axisymmetric jet in a small co-flow, Journal of Hydraulics Research, 40(4), pp 477- 489. doi.org/10.1080/00221680209499890

$$
I_{q}=\int_{0}^{\infty} F(\eta) 2 \pi \eta d \eta=\pi
$$

and defining $\Delta \Delta_{e}=G(\eta)$ and $\left(\Delta^{\prime} u^{\prime}\right) / \Delta_{e} U_{e}=j(\eta)$ we get, for the shape functions associated with the buoyancy terms, the following

$$
\begin{aligned}
& I_{q \Delta}=\int_{0}^{\infty}[F(\eta) G(\eta)+j(\eta)] 2 \pi \eta d \eta=2.0 \\
& I_{\Delta}=\int_{0}^{\infty} G(\eta) 2 \pi \eta d \eta=3.6
\end{aligned}
$$

Where the non-dimensional turbulent flux term $(j(\eta))$ contributes to approximately $16 \%$ of the total flux (Papanicolaou \& List, 1988).

The shape functions can be substituted into the horizontal momentum equation and the equation can made dimensionless in terms of orifice diameter $(d)$ and the initial velocity $\left(U_{0}\right)$, giving:

$$
\frac{d}{d s_{*}}\left[\left(I_{m} U_{e^{*}}^{2} b_{*}^{2}+U_{\infty^{*}} \cos \theta I_{q} U_{e^{*}} b_{*}^{2}\right) \cos \theta\right]=0
$$

where $s^{*}=s / d, x *=x / d, z^{*}=z / d, b *=b / d, r *=r / d, U_{e^{*}}=U_{e} / U_{0}$ and $U_{\infty^{*}}=U_{\infty} / U_{0}$. This equation can then be written as

$$
\frac{d}{d s_{*}}\left[\left(I_{q} U_{e^{*}} b_{*}^{2}+U_{\infty^{*}} \cos \theta \frac{I_{q}^{2}}{I_{m}} b_{*}^{2}\right) \frac{I_{m}}{I_{q}} U_{e^{*}} \cos \theta\right]=\frac{d}{d s_{*}}\left[q_{*} \frac{I_{m}}{I_{q}} U_{e^{*}} \cos \theta\right]=0
$$

Where $q_{*}=I_{q} U_{e^{*}} b{ }^{2}+U_{\infty *} \cos \theta\left(I_{q}{ }^{2} / I_{m}\right) b^{2}$. The first term is due to the Gaussian distribution and the second term due to the turbulent ambient fluid. Similarly for the dimensionless vertical momentum $\left(M_{V^{*}}\right)$ we get

$$
\frac{d}{d s_{*}}\left(q_{*} \frac{I_{m}}{I_{q}} U_{e^{*}} \sin \theta\right)=\frac{I_{\Delta}}{F r_{o}^{2}} \Delta_{*} b_{*}^{2}
$$

where the buoyancy $(\Delta)$ is made dimensionless with respect to the initial buoyancy $\left(\Delta_{0}\right)$. In addition the flux of buoyancy is

$$
I_{q \Delta} U_{e^{*}} \Delta_{*} b_{*}^{2}+U_{\infty^{*}} \cos \theta I_{\Delta} \Delta_{*} b_{*}^{2}=\frac{\pi}{4}\left(1+U_{\infty^{*}}\right)
$$

and this may be written as 
Author accepted version. Final publication as:

Davidson, M.J., Gaskin, S.J. \& Wood, I.R. (2002) A study of a buoyant axisymmetric jet in a small co-flow, Journal of Hydraulics Research, 40(4), pp 477- 489. doi.org/10.1080/00221680209499890

$$
\left(I_{q} U_{e^{*}} b_{*}^{2}+U_{\infty^{*}} \cos \theta \frac{I_{q} I_{\Delta}}{I_{q \Delta}} b_{*}^{2}\right) \frac{I_{q \Delta}}{I_{q}} \Delta_{*}=\frac{\pi}{4}\left(1+U_{\infty^{*}}\right)
$$

and if

$$
\frac{I_{q}}{I_{m}}=\frac{I_{\Delta}}{I_{q \Delta}}
$$

then

$$
q_{*}\left(\frac{I_{q \Delta}}{I_{q}} \Delta_{*}\right)=\frac{\pi}{4}\left(1+U_{\infty}\right)
$$

The experimental values of $I_{q} / I_{m}$ and $I_{\Delta} I_{q \Delta}$ are respectively 1.85 and 1.8. The difference is within the experimental error and thus equation 30 is adopted.

The movement of the jet or plume requires some discussion. The trajectory is governed by the momentum equations in the stationary frame of reference. In this stationary frame of reference the momentum includes all of the turbulent flow (the jet excess velocity with a Gaussian mean distribution and the turbulent ambient flow within it) and hence the dimensionless horizontal momentum $\left(M_{H^{*}}\right)$ is

$$
q *\left(\frac{I_{m}}{I_{q}} U_{e^{*}} \cos \theta+U_{\infty}\right)
$$

Note equation 31 is not a constant as $U_{\infty *} q_{*}$ increases with distance from the source. There is no advection velocity in the vertical momentum equation and thus equation (26) does not change. Hence the geometric equations are

$$
\begin{gathered}
\frac{d x_{*}}{d s_{*}}=\frac{\left(I_{q} U_{e^{*}} b_{*}^{2}+U_{\infty *} \cos \theta \frac{I_{q}^{2}}{I_{m}} b_{*}^{2}\right)\left(\frac{I_{m}}{I_{q}} U_{e^{*}} \cos \theta+U_{\infty^{*}}\right)}{\left(M_{V^{*}}^{2}+M_{H^{*}}^{2}\right)^{1 / 2}} \\
\frac{d z_{*}}{d s_{*}}=\frac{\left(I_{q} U_{e^{*}} b_{*}^{2}+U_{\infty^{*}} \cos \theta \frac{I_{q}^{2}}{I_{m}} b_{*}^{2}\right) \frac{I_{m}}{I_{q}} U_{e^{*}} \sin \theta}{\left(M_{V^{*}}^{2}+M_{H^{*}}^{2}\right)^{1 / 2}}
\end{gathered}
$$

and hence 
Author accepted version. Final publication as:

Davidson, M.J., Gaskin, S.J. \& Wood, I.R. (2002) A study of a buoyant axisymmetric jet in a small co-flow, Journal of Hydraulics Research, 40(4), pp 477- 489. doi.org/10.1080/00221680209499890

$$
\frac{d z_{*}}{d x_{*}}=\frac{\frac{I_{m}}{I_{q}} U_{e^{*}} \sin \theta}{\left(\frac{I_{m}}{I_{q}} U_{e^{*}} \cos \theta+U_{\infty^{*}}\right)}
$$

This formulation reduces to the normal case when the advection velocity $\left(U_{\infty *}\right)$ is zero. For small co-flows (defined by $U_{\infty}$ less than the maximum value of the entrainment velocity) the theory assumes the entrainment is unchanged from the zero cross-flow case. This would be the case when time dependent vortical structures are not greatly displaced by the ambient motion. The non-dimensional form of equation (9) is then

$$
\frac{d}{d s_{*}}\left(q_{*}\right)=2 \pi b_{*} \alpha U_{e^{*}}
$$

It should be noted that using this definition of $q *$ implies that the entrainment is governed by the excess velocity and that the entrained fluid spreads into the turbulent flow, which consists of the excess discharge $\left(I_{q} U_{e} * b *^{2}\right)$ and the turbulent co-flow $\left(U_{\infty *} \cos \theta\left(I_{q}^{2} / I_{m}\right) b *^{2}\right)$.

The initial flow is jet like and the final flow approximates a plume. For a vertical buoyant jet List in Fischer (1979) shows that

$$
\alpha=\alpha_{j}+\left(\alpha_{p}-\alpha_{j}\right)\left(\frac{F r_{p}}{F r_{l}}\right)^{2}
$$

Where $F r_{p}$ is the final constant plume Froude number and $F r_{l}$ is a local Froude number. The final constant Froude number is between 3.4 and 3.7 and the latter was adopted. For the case when the jet was ejected horizontally we then use

$$
\alpha=\alpha_{j}+\left(\alpha_{p}-\alpha_{j}\right)\left(\frac{F r_{p} \sin \theta}{F r_{l}}\right)^{2}
$$

This allows the entrainment constant to be determined when there is either a jet or a plume.

In all experiments there is a zone of flow establishment and for the very small cross-flow it is sufficient to use the no cross-flow conditions. The subsequent experiments are only for a horizontal cross-flow and for this case they show 
Author accepted version. Final publication as:

Davidson, M.J., Gaskin, S.J. \& Wood, I.R. (2002) A study of a buoyant axisymmetric jet in a small co-flow, Journal of Hydraulics Research, 40(4), pp 477- 489. doi.org/10.1080/00221680209499890

that the length of the zone of flow establishment $(x / d)$ is approximately 6 . Furthermore if we neglect the boundary layer within the exit pipe, then for the initial angle of zero the exit velocity $U_{o}$ is given by $U_{e o}+U_{\infty}$. Noting that the value of $U_{e o}$ is constant on the centre-line in this region and that the excess horizontal momentum is conserved, leads

to

$$
\begin{aligned}
& \frac{\pi}{4}\left(U_{e o^{*}}+U_{\infty *}\right) U_{e o^{*}} \\
& =\left(I_{q} U_{e o^{*}} b_{*}^{2}+U_{\infty *} \cos \theta_{i} \frac{I_{q}^{2}}{I_{m}} b_{*}^{2}\right) \frac{I_{m}}{I_{q}} U_{e o^{*}} \cos \theta_{i}=q_{*} \frac{I_{m}}{I_{q}} U_{e o^{*}} \cos \theta_{i}
\end{aligned}
$$

where Ayoub (1971) experiments show that

$$
\tan \theta_{i}=\frac{10}{F r_{o}^{2}}
$$

This allows the value of $b *$ to be calculated. Finally the value of the vertical momentum at the end of the zone of flow establishment is

$$
\left(I_{q} U_{e o^{*}} b_{*}^{2}+U_{\infty *} \cos \theta_{i} \frac{I_{q}^{2}}{I_{m}} b_{*}^{2}\right) \frac{I_{m}}{I_{q}} U_{e o^{*}} \sin \theta_{i}=q_{*} \frac{I_{m}}{I_{q}} U_{e o^{*}} \sin \theta_{i}
$$

With these initial conditions the solutions for the trajectory, the width, the dilution and the velocity of the flow can be obtained.

\section{Experiments}

Data from the present study and those carried out by Davidson and Pun will be compared with the results of the theoretical analysis described in the previous section. Both sets of experiments were conducted with a neutral or negatively buoyant effluent (salt water) in fresh water contained in a glass-sided tank and in each case the cross-flow was obtained by towing the plume or jet. Both tanks were large enough to prevent boundary effects, the present study was carried out in a tank that was $6 \mathrm{~m}$ long, $1.5 \mathrm{~m}$ wide and $1.1 \mathrm{~m}$ deep and Davidson's tank was $15 \mathrm{~m}$ long, $2 \mathrm{~m}$ wide and 1.6m deep. In both studies Laser-induced Fluorescence (LIF) was used to record the behaviour of the jet or plume and measurements of the mean and fluctuating concentrations were obtained. However, the experiments differ in that for the present study most of the plumes are ejected horizontally, whereas in Davidson's study the 
Author accepted version. Final publication as:

Davidson, M.J., Gaskin, S.J. \& Wood, I.R. (2002) A study of a buoyant axisymmetric jet in a small co-flow, Journal of Hydraulics Research, 40(4), pp 477- 489. doi.org/10.1080/00221680209499890

flows were discharged vertically. In addition for the present study particle image measurements (PIV) were employed to obtain entrainment velocities. A more detailed description of the present experiments can be found in Gaskin (1995). These PIV measurements were crucial to the development of the theory and hence they will be discussed first.

\section{3a Verification of the assumption behind the theory}

The present experiments were performed with a buoyant jet with a densimetric Froude number of 10, ejected horizontally as is shown in figure 5a. Initially the focus was on the entrainment velocities beyond the turbulent region. The instantaneous entrainment velocities near the turbulent fluid vary as the large-scale periodic motions engulf the flow intermittently. However the mean entrainment velocities could be obtained using a PIV technique, in which the ambient fluid was seeded with particles and a sheet of laser light illuminated a section through the flow (figure 5b). Pairs of images separated by a small time interval were analyzed using the PIV analysis of Steven and Coates (1994). This system uses a pattern matching technique to find the displacement of sub-images over the time interval separating the images. The results after analysis and averaging over time are presented as an average velocity vector map of the flow. To measure velocities in vertical and horizontal planes appropriate laser light sheets were created using combinations of rotating and parabolic mirrors. Measurements in the vertical plane were made on the flow centreline.

For a horizontally discharged buoyant jet, with a Froude number of 10, entrainment velocities were measured with and without an ambient velocity. Examples of these measurements are shown in figure 6. Figure 6a shows the velocity vector map for zero ambient velocity and figure $6 \mathrm{~b}$ shows the same horizontally discharged buoyant jet with a ambient velocity $\left(U_{\infty}\right)$ of $2.1 \mathrm{~mm} / \mathrm{s}\left(U_{o} / U_{o}=.0056\right)$. In spite of the obvious differences in the velocities outside of the turbulent flow in these figures, the trajectory of the buoyant flow is almost unchanged by the presence of the small cross-flow. In figure $6 \mathrm{c}$, an advecting velocity of $2.1 \mathrm{~mm} / \mathrm{s}$ has been added to the velocity field in figure 6a. While there are some differences between the velocity fields in figures $6 \mathrm{~b}$ and $6 \mathrm{c}$ the velocity fields are similar. (The differences are particularly evident close to the port, where there is a region where the buoyant flow feels the 
Author accepted version. Final publication as:

Davidson, M.J., Gaskin, S.J. \& Wood, I.R. (2002) A study of a buoyant axisymmetric jet in a small co-flow, Journal of Hydraulics Research, 40(4), pp 477- 489. doi.org/10.1080/00221680209499890

wake from the port.) Thus the assumption that in a weak cross-flow the velocities outside of the turbulent flow can be obtained by superimposing the zero cross-flow entrainment velocities with the advecting ambient velocity, is within the experimental errors. This should not be particularly surprising since the deflection of the flow is minimal and the entrainment velocities outside the turbulent flow are irrotational.

Figure $7 \mathrm{a}$ shows the entrainment velocities in a horizontal section taken $400 \mathrm{~mm}$ below the plume orifice with zero cross-flow. Figures $6 \mathrm{a}$ and $7 \mathrm{a}$ verify the traditional view of entrainment velocities as an irrotational flow into a sink. Noting that the velocities at a large distance from the plume $(300 \mathrm{~mm})$ are approximately horizontal, the total entrainment into the buoyant flow can be computed. This calculation gives a sink of strength $\left(q_{S}\right)$ of $0.0025 \mathrm{~m}^{3} / \mathrm{ms}$.

Figure $7 \mathrm{~b}$ shows the velocity field outside the turbulent flow in the same section, $400 \mathrm{~mm}$ below the plume orifice, with an ambient velocity of $2.1 \mathrm{~mm} / \mathrm{s}$. Again the velocity field outside of the turbulent flow is altered significantly by the presence of the weak cross-flow. Figure $7 \mathrm{c}$ shows the simulated velocity field constructed using the case with no ambient velocity (Figure 7a) to which a velocity of $2.1 \mathrm{~mm} / \mathrm{s}$ has been added. The similarities between Figure $7 \mathrm{~b}$ and $7 \mathrm{c}$ are to be noted.

The comparisons in figures 6 and 7 assume that the value of the sink strength $q_{S}$ does not change with the presence of a very small cross-flow. The accuracy of this assumption can be further assessed by subtracting the ambient velocity from the measured velocities in Figure $7 \mathrm{~b}$ and making use of the velocities at a radius of $300 \mathrm{~mm}$ from the flow centreline to determine the sink strength. The value determined was $0.0026 \mathrm{~m}^{3} / \mathrm{ms}$ and this confirms that any discrepancy between the no cross-flow and the weak cross-flow case is within experimental error. It should be noted in Figure $6 \mathrm{~b}$ that at $400 \mathrm{~mm}$ the streamlines are almost horizontal except near to the turbulent buoyant flow.

Figure $8 \mathrm{a}$ is the experimental velocity field with a cross-flow of $6.1 \mathrm{~mm} / \mathrm{s}\left(U_{o d} U_{o}=0.016\right)$ and calculating $q_{S}$ as above we get $0.004 \mathrm{~m}^{3} / \mathrm{ms}$. This is larger than the zero cross-flow value determine from figure $7 \mathrm{a}$. Figure $8 \mathrm{~b}$ is the simulated velocity vector field in the horizontal section, with the larger value of $q_{S}$ and a cross-flow velocity of 6.1 $\mathrm{mm} / \mathrm{s}$. As in the previous case the agreement is very satisfactory. 
Author accepted version. Final publication as:

Davidson, M.J., Gaskin, S.J. \& Wood, I.R. (2002) A study of a buoyant axisymmetric jet in a small co-flow, Journal of Hydraulics Research, 40(4), pp 477- 489. doi.org/10.1080/00221680209499890

Figure $9 \mathrm{a}$ is the experimental velocity field with an increased cross-flow of $11.1 \mathrm{~mm} / \mathrm{s}\left(U_{o d} / U_{o}=0.03\right)$ and the estimated $q_{S}$ with the cross-flow is $0.01 \mathrm{~m}^{3} / \mathrm{ms}$. Figure $9 \mathrm{~b}$ is the simulated velocity vector field in the horizontal section, with the new sink value and the cross-flow velocity of $11.1 \mathrm{~mm} / \mathrm{s}$. Again the agreement between the simulated and actual velocity fields is satisfactory. For all cases considered here, a realistic simulated velocity field could be calculated with an appropriate sink in the tank (images of this sink exist outside the tank walls) and a superimposed uniform cross-flow.

It is evident from this experimental study that the assumption that the velocities outside the turbulent flow can be constructed by superimposing the entrainment velocities, for the equivalent no cross-flow case, with the advected velocity is correct to within the experimental errors. However, this is only true for the lower cross-flow velocity $(2.1$ $\mathrm{mm} / \mathrm{s}$ ), whereas for the cross-flow velocities of 6.1 and $11.1 \mathrm{~mm} / \mathrm{s}$ the entrainment (sink strength) increases with this velocity. It is to be noted that with very small cross-flows (such as $2.1 \mathrm{~mm} / \mathrm{s}$ ) the changes in the trajectories are small and the change in value of the average maximum buoyant jet velocity $\left(U_{e}\right)$ at a particular location will be also small. Hence the turbulent structure of the flow, which is created by the excess velocity, is essentially unchanged and the entrainment is not therefore expected to change. For higher ambient velocities $(6.1$ and $11.1 \mathrm{~mm} / \mathrm{s}$ in these experiments) the flow structure is altered by the presence of the ambient velocity and the entrainment increases.

Davidson and Pun (1999) and Pun and Davidson (1999) obtained more information on the tracer concentration distribution for the case of a jet or plume released vertically in a cross-flow. Their LIF measurements showed that there were only small deviations from the Gaussian distribution assumed for a turbulent jet or plume flow in a still ambient fluid. In addition the mean turbulent fluctuations of these flows in a weak current were also shown to be comparable with an equivalent jet or plume in a still ambient fluid.

\section{3b The predictions from the theory}

Numerous experiments have been carried out for the case where there is no cross-flow. For the vertical release of a 
Author accepted version. Final publication as:

Davidson, M.J., Gaskin, S.J. \& Wood, I.R. (2002) A study of a buoyant axisymmetric jet in a small co-flow, Journal of Hydraulics Research, 40(4), pp 477- 489. doi.org/10.1080/00221680209499890

jet or a plume the equations reduce to the classic equations and no verification is required. When a buoyant jet is ejected horizontally with no crossflow there have been many measurements of the flow trajectories and figure 10 shows a comparison with the theory. As expected the agreement is very satisfactory.

For the very small cross-flows the entrainment and the spread of are the same as in a jet or plume in a still ambient fluid. Davidson and Pun experiments have verified that this is the case. Their experiments were conducted for the vertically ejected jets and plumes and hence $\theta$ was $\pi / 2$. For this case the trajectory equation (34) reduces to

$$
\frac{d z_{*}}{d x_{*}}=\frac{I_{m}}{I_{q}} \frac{U_{e^{*}}}{U_{\infty *}}
$$

For the jet the vertical momentum equation (26) and the continuity equation (35) yields

$$
U_{e^{*}}=\frac{I_{q}}{\left(\pi I_{m}\right)^{1 / 2}} \frac{1}{4 \alpha z_{*}}
$$

Thus with the entrainment constant for a jet and neglecting the zone of flow establishment, the trajectory can be written as

$$
z_{*}=\frac{I_{m}^{1 / 4}}{\pi^{1 / 4} U_{\infty^{*}}^{1 / 2}} \frac{1}{(2 \alpha)^{1 / 2}} x_{*}^{1 / 2}=\frac{2.6}{U_{\infty^{*}}^{1 / 2}} x_{*}^{1 / 2}
$$

Predictions from equation (42) are compared with data from Davidson and Pun (1999) in figure 11. The agreement is well within the experimental errors.

For a plume the vertical momentum equation (26) and the continuity equation (35) yields for the vertical velocity

$$
U_{e^{*}}=\left(\frac{25 I_{q}^{2} I_{\Delta}}{192 I_{m} I_{q \Delta} \pi \alpha^{2} \operatorname{Fr}_{o}^{2}}\right)^{1 / 3} \frac{1}{z_{*}^{1 / 3}}
$$

Hence

$$
\frac{d z_{*}}{d x_{*}}=\frac{1}{U_{\infty^{*}}}\left(\frac{25 I_{m}^{2} I_{\Delta}}{192 I_{q} I_{q \Delta} \pi \alpha^{2} F r_{o}^{2}}\right)^{1 / 3} \frac{1}{z_{*}^{1 / 3}}
$$

Neglecting the zone of flow establishment and inserting the appropriate value of the entrainment constant for a pure plume we get 
Author accepted version. Final publication as:

Davidson, M.J., Gaskin, S.J. \& Wood, I.R. (2002) A study of a buoyant axisymmetric jet in a small co-flow, Journal of Hydraulics Research, 40(4), pp 477- 489. doi.org/10.1080/00221680209499890

$$
z_{*}=\left(\frac{4}{3 U_{\infty^{*}}}\right)^{3 / 4}\left(\frac{25 I_{m}^{2} I_{\Delta}}{192 I_{q} I_{q \Delta} \pi \alpha^{2} F r_{o}^{2}}\right)^{1 / 4} x_{*}^{3 / 4}=\frac{2.2}{U_{\infty *}^{3 / 4} F r_{0}^{1 / 2}} x_{*}^{3 / 4}
$$

In figure 12 the experimental data from Pun and Davidson (1999) is compared with predictions from equation (45) and again these predictions are well within the experimental errors.

For this case the transition to an advected thermal starts when

$$
\frac{z U_{\infty}^{3}}{q_{\Delta o}}=c
$$

Where $c$ is a constant. Using the plume solution up to the beginning of the transition gives

$$
\frac{U_{e}}{U_{\infty}}=\frac{0.78}{\alpha^{2 / 3} c^{1 / 3}}\left(\frac{4}{\pi}\right)^{1 / 3}
$$

Pun and Davidson suggest that the transition is initiated when the constant " $c$ " has a value of 0.5. Adopting this value and using the entrainment constant for the plume we get

$$
\frac{U_{\infty}}{\alpha U_{e}}=2.1
$$

It should be noted that this transition value is relatively insensitive to the value of $c$. It is tempting to suggest that the evolution of the vortex pair flow is determined by the resolved part of the ambient flow at right angles to $U_{e^{*}}$ and we therefore write

$$
\frac{U_{\infty} \sin \theta}{\alpha U_{e}}=2.1
$$

With a Froude number of 10 and ambient velocities of zero, 2.1, 6.1 and $11.2 \mathrm{~mm} / \mathrm{s}$ the entrainment was measured directly at $z / d=64$. Making use of the plume calculations, we can compute the values of $U_{\infty} \sin \theta / \alpha U_{e}$ at this location. Here $\sin \theta$ is approximately one and thus $U_{\infty} \sin \theta / \alpha U_{e} \approx U_{\infty} / \alpha U_{e}$. It appears in figure 13 that the transition has already begun occurring for values of $U_{\infty} \sin \theta / \alpha U_{e}$ close to one, but the transition has not started for values of this ratio less than 0.5 . This suggests that the cross-flow transition values are different for a plume ejected horizontally and a plume ejected vertically, indicating that the vortex pair forms closer to source in the horizontally 
Author accepted version. Final publication as:

Davidson, M.J., Gaskin, S.J. \& Wood, I.R. (2002) A study of a buoyant axisymmetric jet in a small co-flow, Journal of Hydraulics Research, 40(4), pp 477- 489. doi.org/10.1080/00221680209499890

discharged case. However a more detailed investigation is required before conclusions can be drawn on this issue.

In the present study trajectory measurements were also made for discharges with a Froude number of 5 and ambient velocities ranging from 0 to $8.7 \mathrm{~mm} / \mathrm{s}$. In these cases the Reynolds numbers were less than 2000 and the flow was initially laminar and thus the initial momentum was corrected for the laminar velocity distribution. Computed trajectories and the value of $\alpha U_{e} / U_{\infty} \sin \theta$ are compared with the experimental data for ambient velocities of zero, $2.7 \mathrm{~mm} / \mathrm{s}, 5.7 \mathrm{~mm} / \mathrm{s}$ and $8.5 \mathrm{~mm} / \mathrm{s}$ in figure 14 . The computed values are close to the experimental trajectories for the smaller co-flows (up to the ambient velocity of $5.7 \mathrm{~mm} / \mathrm{s}$ ). For the larger co-flow the theoretical model with an entrainment constant appropriate to a jet or a plume in still ambient fluid fails. The values of $U_{\infty} \sin \theta / \alpha U_{e}$ exceed one $\left(\alpha U_{e} / U_{\infty} \sin \theta\right.$ less than one in figure 14) where the discrepancies occur and this suggests that the advected thermal begins playing a significant role when

$$
\frac{U_{\infty} \sin \theta}{\alpha U_{e}} \approx 1
$$

In a similar manner the trajectories were determined for a Froude number of 10 and 15 for ambient velocities ranging from 0 to $25.2 \mathrm{~mm} / \mathrm{s}$. Data obtained for a Froude number of 10 and ambient velocities of zero, 5.7, 11.3 and $16.9 \mathrm{~mm} / \mathrm{s}$ are compared with computed trajectories and the value of $\alpha U_{e} / U_{\infty} \sin \theta$ in Figure 15. Again the computed values are close to the experimental trajectories where $U_{\infty} \sin \theta / \alpha U_{e}$ is less than 1 . In figure 16 trajectory data is presented for flow with a Froude number of 15 and ambient velocities of zero, 8.5, 16.9 and 25.2mm/s. For all of the non-zero ambient velocity cases $U_{\infty} \sin \theta / \alpha U_{e}$ quickly exceeds 1 and hence the model only provides reasonable predictions for the zero co-flow case.

It is concluded that the theory derived is likely to be satisfactory if $U_{\infty} \sin \theta / \alpha U_{e}$ is less than a transition value and that this transition value is between 0.5 and 1 .

\section{Conclusions}


Author accepted version. Final publication as:

Davidson, M.J., Gaskin, S.J. \& Wood, I.R. (2002) A study of a buoyant axisymmetric jet in a small co-flow, Journal of Hydraulics Research, 40(4), pp 477- 489. doi.org/10.1080/00221680209499890

It has been shown experimentally that with a weak cross-flow the average entrainment velocity outside of the turbulent flow can be simulated with a uniform ambient flow superimposed on a series of sinks on the axis of the jet. This extends the work of Taylor (1958) for the case of a still fluid. Further, when the local velocity ratio (defined as the component of the ambient flow velocity perpendicular to the turbulent flow divided by the entrainment velocity) is less than a critical value $(\approx 1)$, the entrainment is unaffected by the ambient velocity. Beyond this the strength of the sinks are shown to increase as the transition to strongly-advected behaviour begins.

An integral model has been developed based on the information obtained from these and other recent experiments. Predictions from the theory show good agreement with data obtained for the case where there is no cross-flow and the cases were the flow is ejected either vertically or horizontally into a weak cross-flow. The theory assumes the flow is deflected because of the entrained ambient fluid momentum, that is, there is no drag force acting on the flow.

\section{References}

Abraham, G. (1963) "Jet Diffusion in Stagnant Ambient Fluid" Delft Hydraulics Laboratory Pub. No 29.

Albertson, M. L., Diad, Y. B., Jonson, R. A. and Rouse, H. (1948) "Diffusion of submerged jets" Trans. Am. Soc. Civ. Eng. Vol. 115, 639-664.

Ayoub, G. M. (1971) "Behaviour of a buoyant in a flowing environment" Ph.D. Thesis, University of London, U.K.

Davidson, M. J. (1989) "The behaviour of single and multiple horizontally discharged buoyant jets in a nonturbulent ambient fluid", Report No. 89-3, Dept. of Civil Eng., University of Canterbury, N.Z. 
Author accepted version. Final publication as:

Davidson, M.J., Gaskin, S.J. \& Wood, I.R. (2002) A study of a buoyant axisymmetric jet in a small co-flow, Journal of Hydraulics Research, 40(4), pp 477- 489. doi.org/10.1080/00221680209499890

Davidson, M. J. and Pun, K. L. (1999) "Weakly-deflected jets in a cross-flow", Journal of Hydraulic Engineering, ASCE, 125, No. 1., 47-58.

Gaskin, S. (1995) "Single buoyant jets in a crossflow and the advected line thermal", Ph.D. Thesis, Dept. of Civil Eng., University of Canterbury, N.Z.

Gaskin, S. and Wood, I. R. (1999) "The axisymmetric and the plane jet in a coflow" submitted.

Jirka,G. H. and Harleman, D. R. F. (1979) "Stability and mixing of vertical plane jets in a confined depth", J. Fluid Mech., 94, 275-304.

Hussien, H. J., Capp, S. P. and Perry, A. E., (1994) "Velocity measurements in a high-Reynolds-number momentum conserving, axisymmetric, turbulent jet", J. Fluid Mech., 258, 31-75.

Kotsovinos, N. E. (1975) "A study of entrainment and turbulence in a plane buoyant jet", Report No KH-R-32, California Institute of Technology, Pasadena California, 306p.

List, E. J. and Imberger, J. (1973) "Turbulent entrainment in buoyant jets and plumes", J. Hyd. Div., ASCE, 99(9), $1461-1474$

List, E. J in Fischer, H. B. List, E. J. Koh, R. C. Y. Imberger, J. and Brooks, N. H. (1979) "Mixing in Inland and Coastal Waters", Academic Press.

Morton, B., Taylor, G. I .and Turner, J. S. (1956) "Turbulent gravitational convection from maintained and instantaneous source", Proc. Royal Society, London, A234, 1-23.

Papanicolaou, P. N. and List, E. J. (1988) "Investigations of round vertical turbulent buoyant jets", J. Fluid Mech., 
Author accepted version. Final publication as:

Davidson, M.J., Gaskin, S.J. \& Wood, I.R. (2002) A study of a buoyant axisymmetric jet in a small co-flow, Journal of Hydraulics Research, 40(4), pp 477- 489. doi.org/10.1080/00221680209499890

$195,341-391$

Papantoniou, D. and List, E. J. (1989) "Large-scale structure in the far field of buoyant jets", J. Fluid Mech., 209, $151-190$

Pun, K.L., and Davidson, M.J. (1999) "On the behavior of advected plumes and thermals", J. Hyd. Res., IAHR, 37 , No. 4., pp. 519-540.

Rouse, H., Yih, C. S. and Humphries, H. W., (1952) "Gravitational convection from a boundary source", Tellus 4, $201-210$

Scorer, R. S. (1958) "Natural Aerodynamics", Pergamon Press, London 312p.

Stevens, C. L. and Coates, M. J. (1994) "Applications of a maximised cross-correlation technique for resolving velocity fields in laboratory experiments", Journal of Hydraulic Research, IAHR, Vol. 32(2), 195-212.

Taylor, G. I. (1958) "Flow Induced by jets", J. Aero. Sci., 25, 464-465.

Turner, J. S. (1973)"Buoyancy Effects in Fluids", Cambridge University Press, Cambridge, U.K., 367p. 
Author accepted version. Final publication as:

Davidson, M.J., Gaskin, S.J. \& Wood, I.R. (2002) A study of a buoyant axisymmetric jet in a small co-flow, Journal of Hydraulics Research, 40(4), pp 477- 489. doi.org/10.1080/00221680209499890

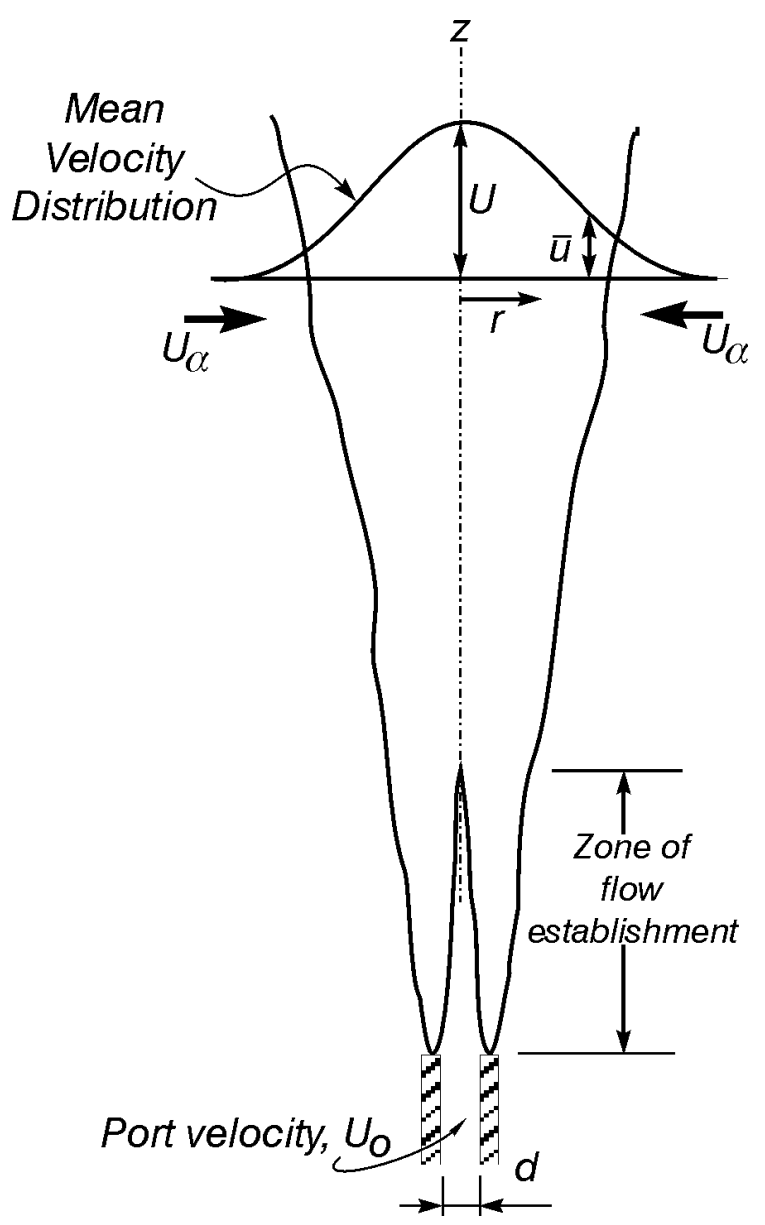

Figure 1. The nomenclature for the jet and plume. Note $u$ is time averaged buoyant jet velocity at radius $r$ and $U$ is the time averaged centre-line velocity. The mean velocity distribution is Gaussian with a length scale of $b$ and for the tracer (jet) or buoyancy (plume) Gaussian distribution the length scale is $\lambda b$. The diameter of the exit pipe is $d$ and the average exit velocity $U_{0}$. 
Author accepted version. Final publication as:

Davidson, M.J., Gaskin, S.J. \& Wood, I.R. (2002) A study of a buoyant axisymmetric jet in a small co-flow, Journal of Hydraulics Research, 40(4), pp 477- 489. doi.org/10.1080/00221680209499890

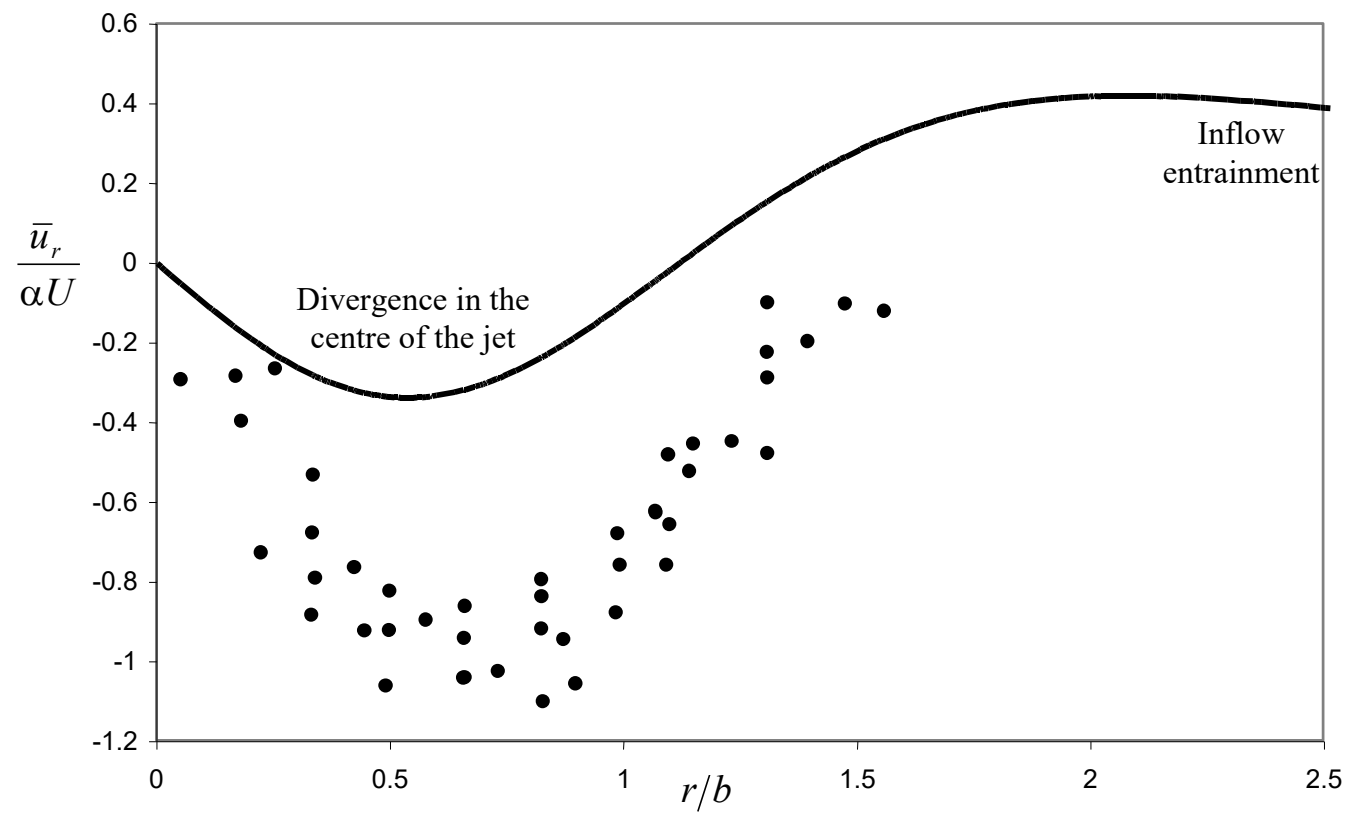

Figure 2a. The experimental measurements of the radial velocities for a jet (Albertson et al 1950) are compared with the theoretical results that are based on the Gaussian distribution. The radial velocity is made dimensionless with the normal entrainment velocity (based on centre line velocity) and distance is made dimensionless with $b$.

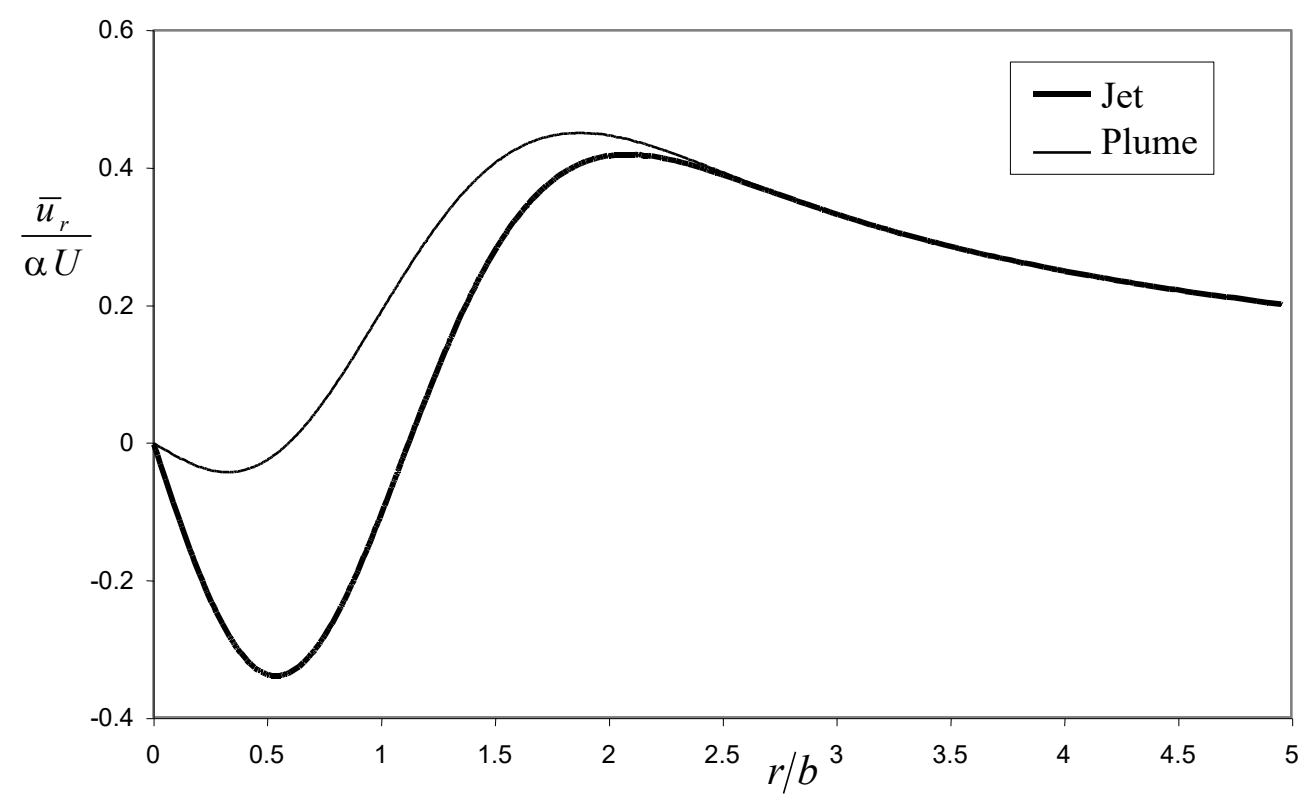

Figure $2 \mathrm{~b}$. The radial velocities for a jet and a plume based on the Gaussian distribution. The radial velocity is made 
Author accepted version. Final publication as:

Davidson, M.J., Gaskin, S.J. \& Wood, I.R. (2002) A study of a buoyant axisymmetric jet in a small co-flow, Journal of Hydraulics Research, 40(4), pp 477- 489. doi.org/10.1080/00221680209499890

dimensionless with the normal entrainment velocity (based on centre line velocity) and distance is made dimensionless with $b$.

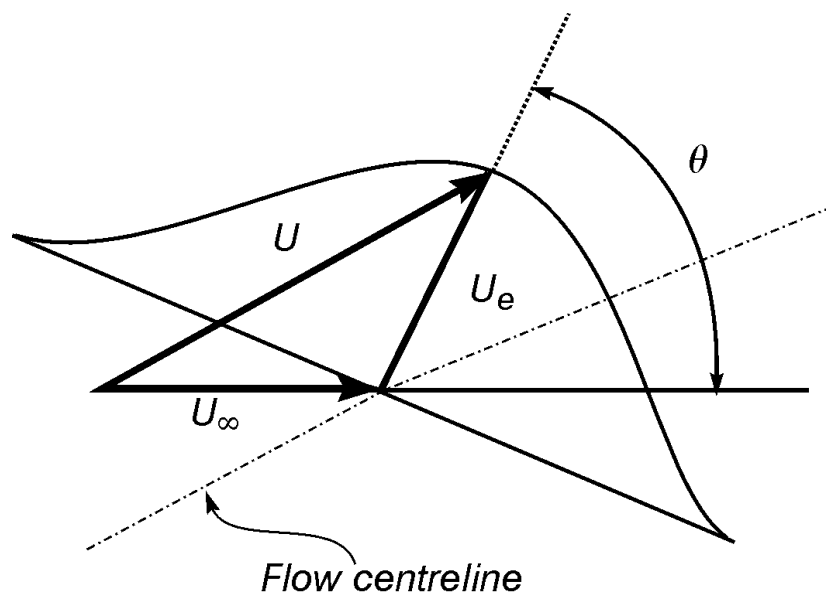

Figure 3. The assumed Gaussian distribution of excess velocity in the advected buoyant jet.

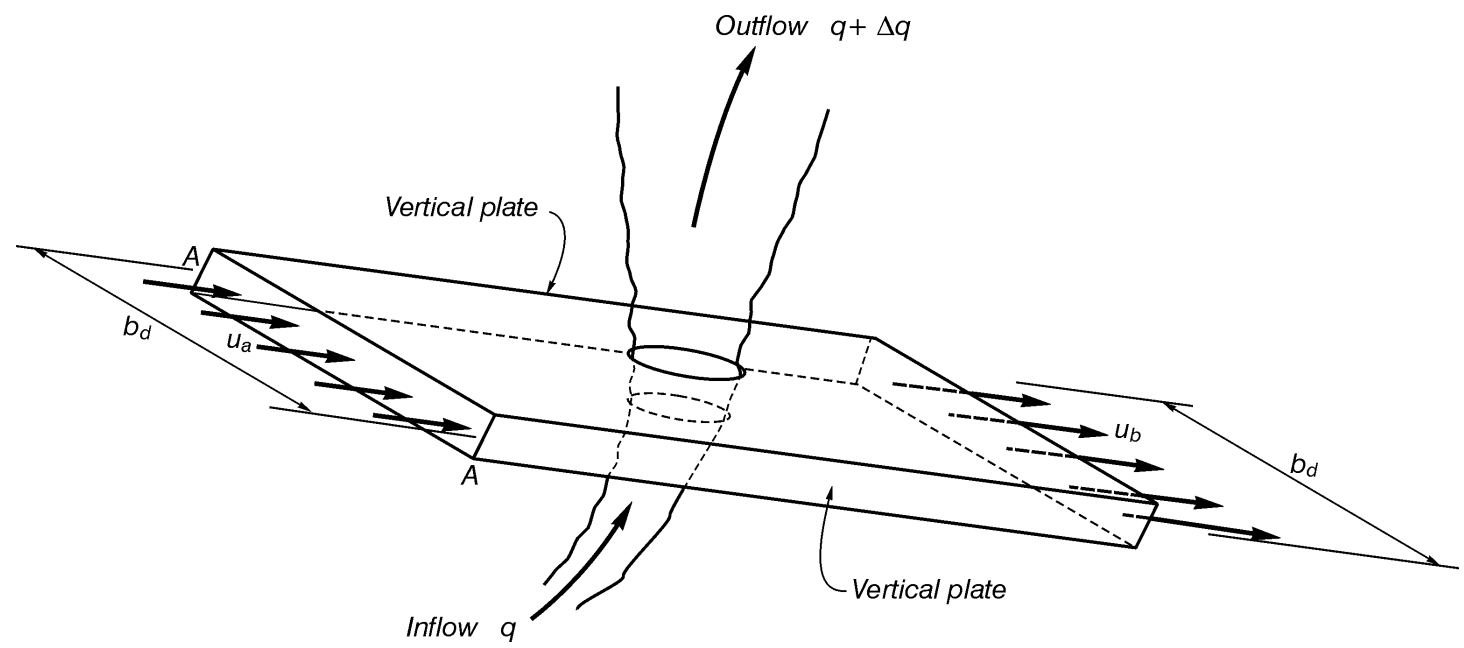

Figure 4. The control volume employed to analyse the flow. 
Author accepted version. Final publication as:

Davidson, M.J., Gaskin, S.J. \& Wood, I.R. (2002) A study of a buoyant axisymmetric jet in a small co-flow, Journal of Hydraulics Research, 40(4), pp 477- 489. doi.org/10.1080/00221680209499890

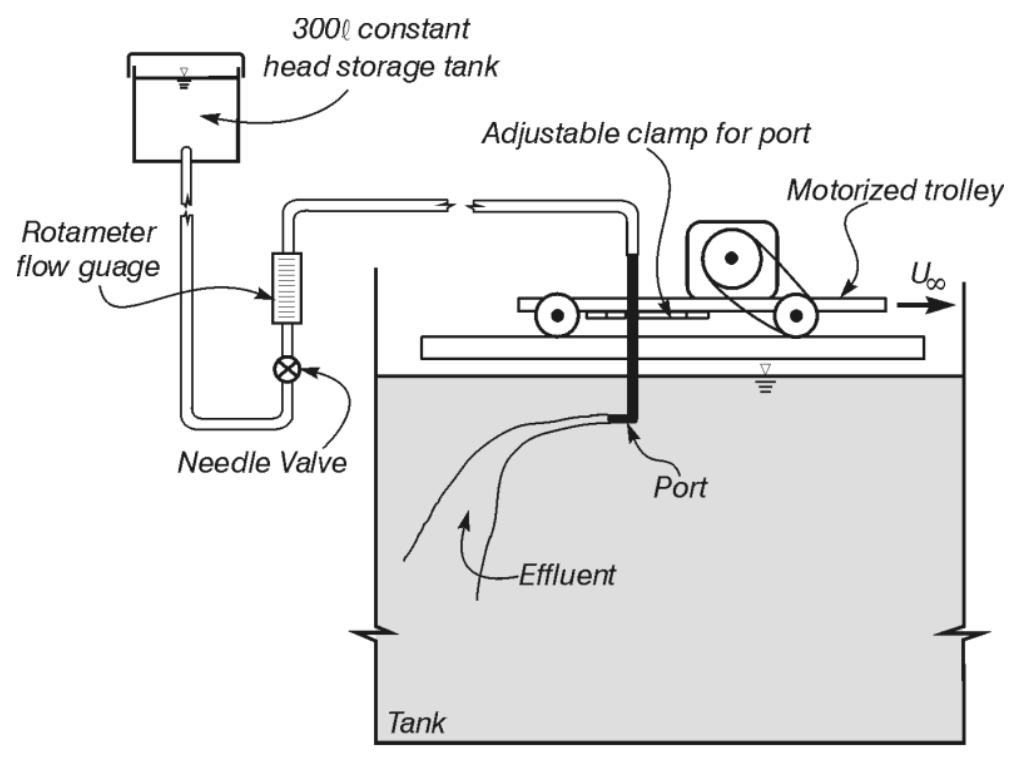

Elevation

Figure 5a. The experimental configuration for studying buoyant jets in a coflowing ambient fluid.

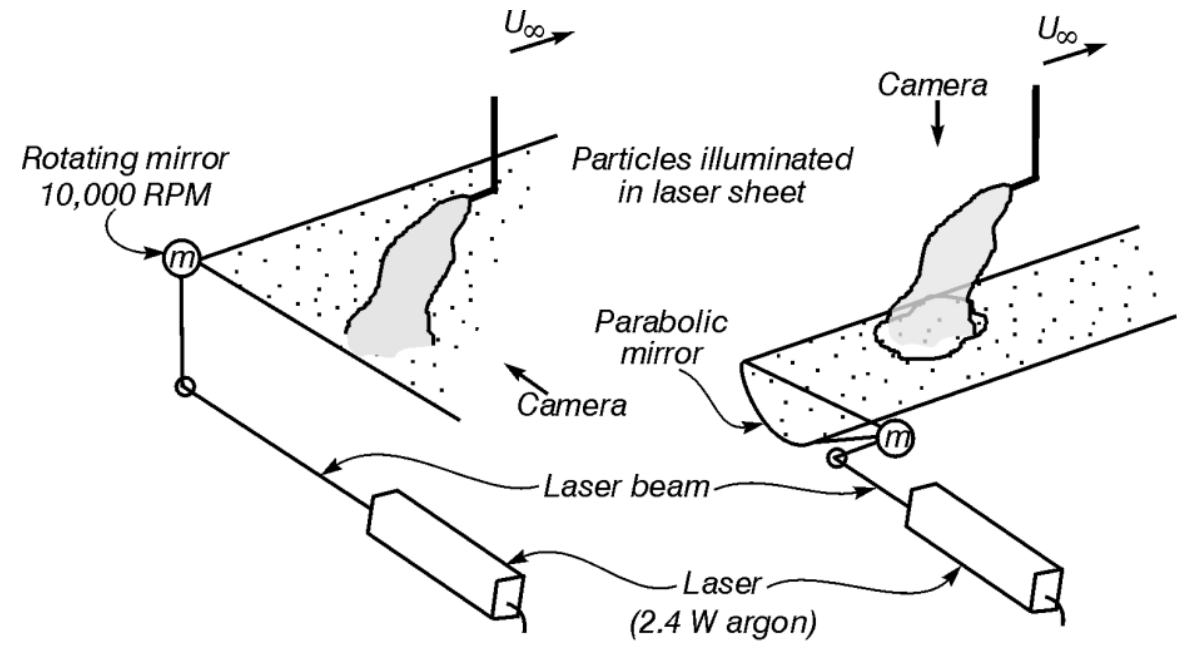

Vertical Section

Horizontal Section

Figure 5b. The laser illumination system employed to study the buoyant flow. 
Author accepted version. Final publication as:

Davidson, M.J., Gaskin, S.J. \& Wood, I.R. (2002) A study of a buoyant axisymmetric jet in a small co-flow, Journal of Hydraulics Research, 40(4), pp 477- 489. doi.org/10.1080/00221680209499890

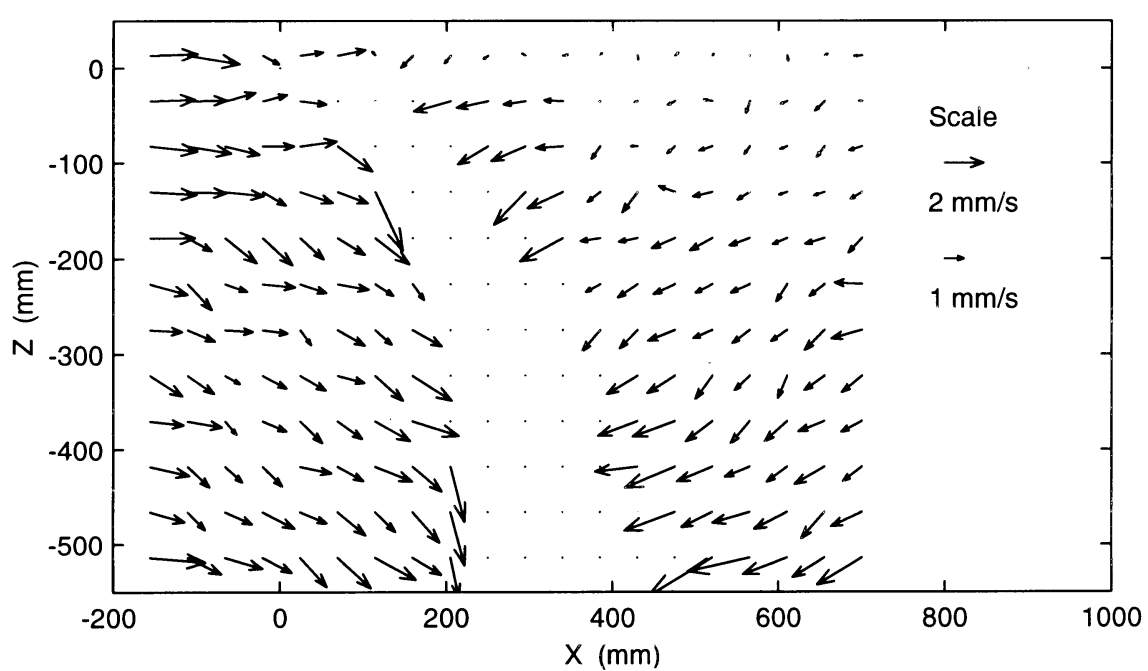

Figure 6a. The velocity vectors in the irrotational region of a buoyant jet ejected horizontally with a Froude number of 10 and zero ambient velocity. The vectors are measured in a vertical plane through the flow centreline.

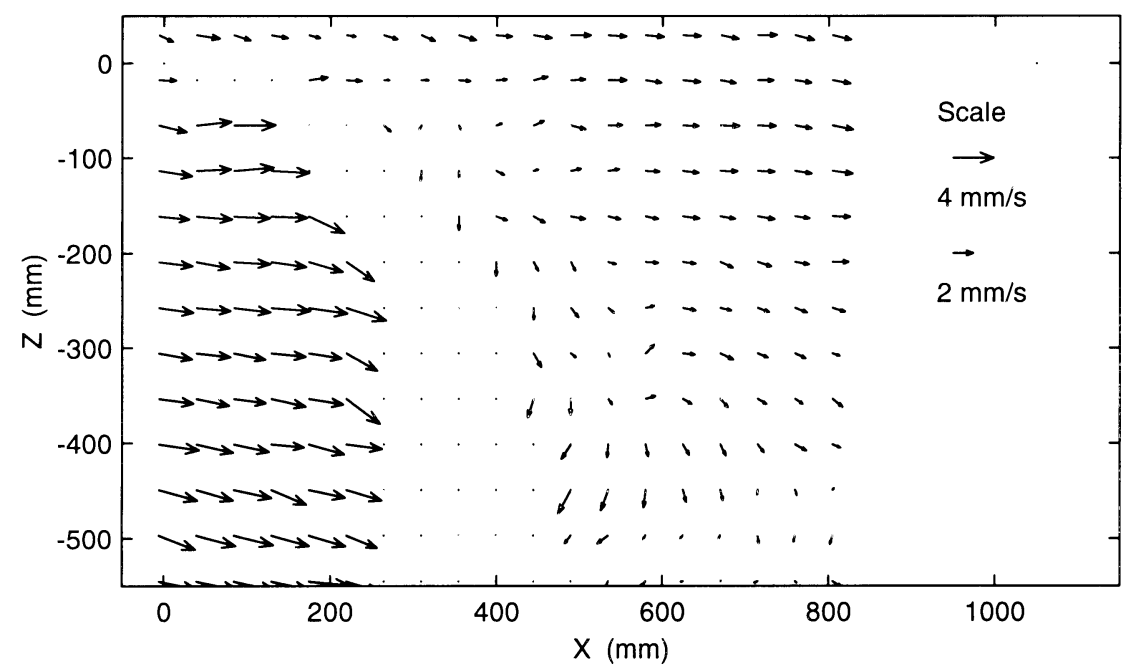

Figure $6 \mathrm{~b}$. The velocity vectors in the irrotational region of a buoyant jet ejected horizontally with a Froude number of 10 and a coflow of $2.1 \mathrm{~mm} / \mathrm{s}$. The vectors are measured in vertical plane through the centreline. 
Author accepted version. Final publication as:

Davidson, M.J., Gaskin, S.J. \& Wood, I.R. (2002) A study of a buoyant axisymmetric jet in a small co-flow, Journal of Hydraulics Research, 40(4), pp 477- 489. doi.org/10.1080/00221680209499890

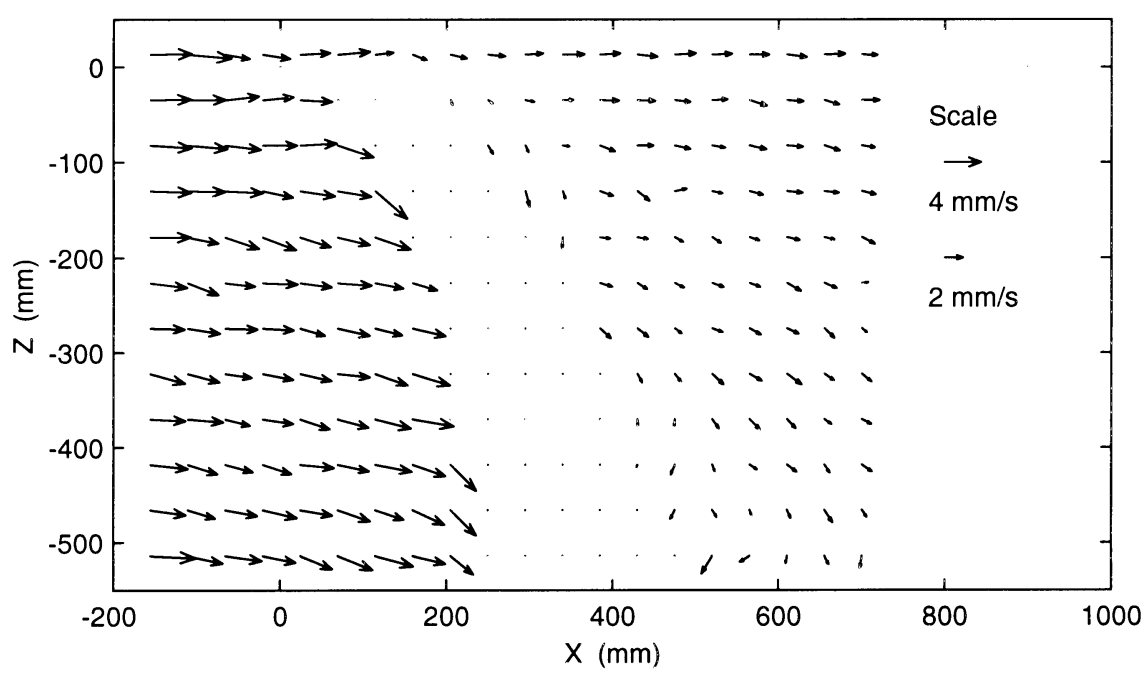

Figure 6c. The velocity vectors for a Froude number of 10 with a coflow of $2.1 \mathrm{~mm} / \mathrm{s}$. This figure is constructed by adding the coflow of $2.1 \mathrm{~mm} / \mathrm{s}$ to Figure $6 \mathrm{a}$. The vectors are in a vertical plane through the centreline.

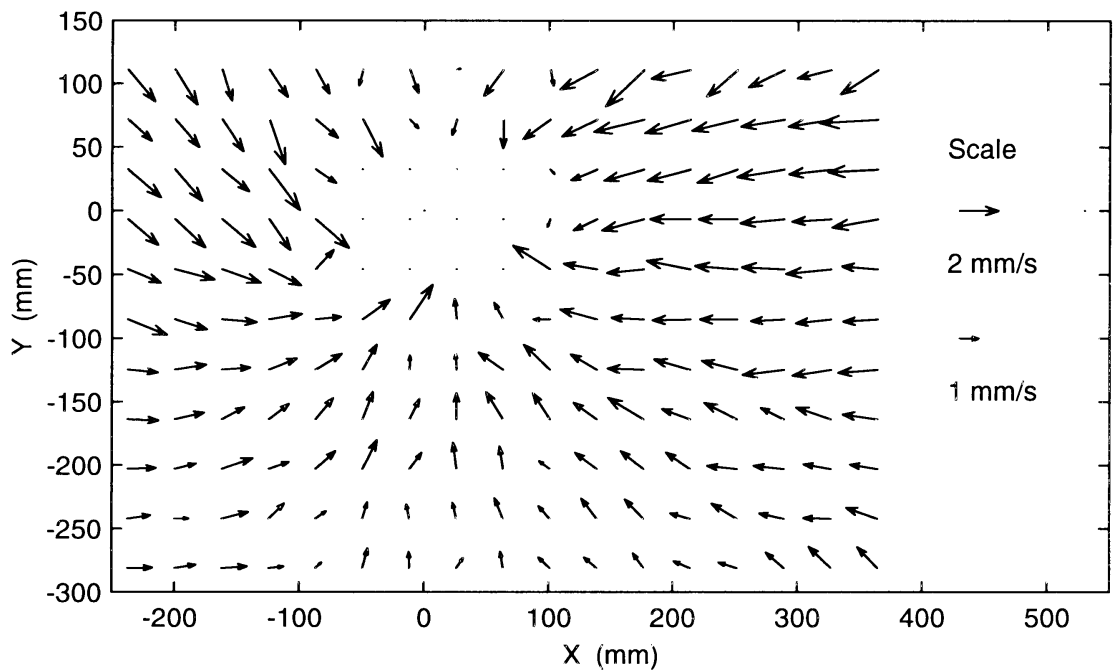

Figure 7a. The velocity vectors in the irrotational region for a buoyant jet ejected horizontally with a Froude number of 10 and zero ambient velocity. The vectors are horizontal and are measured in a plane $400 \mathrm{~mm}$ below the port. The calculated sink value is $0.0025 \mathrm{~m}^{3} / \mathrm{s}$. 
Author accepted version. Final publication as:

Davidson, M.J., Gaskin, S.J. \& Wood, I.R. (2002) A study of a buoyant axisymmetric jet in a small co-flow, Journal of Hydraulics Research, 40(4), pp 477- 489. doi.org/10.1080/00221680209499890

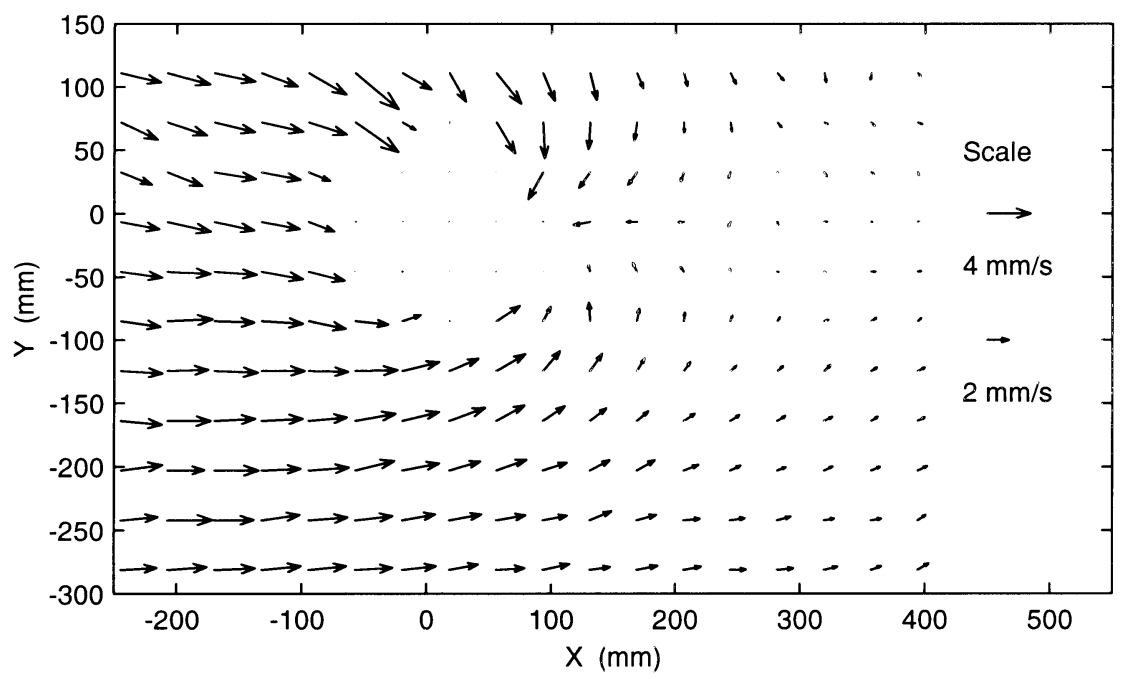

Figure $7 \mathrm{~b}$. The velocity vectors in the irrotational region for a buoyant jet ejected horizontally with a Froude number of 10 and a ambient velocity of $2.1 \mathrm{~mm} / \mathrm{s}$. The vectors are horizontal and are measured in a plane $400 \mathrm{~mm}$ below the port.

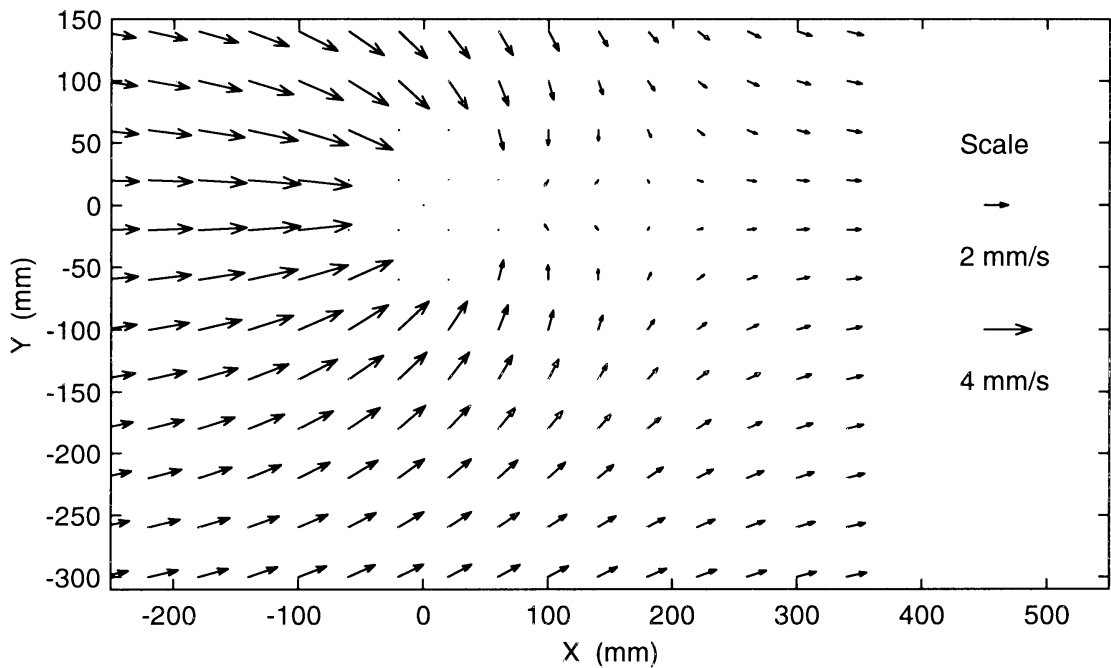

Figure 7c. The velocity vectors for a Froude number of 10 and a coflow of $2.1 \mathrm{~mm} / \mathrm{s}$. This is constructed by adding the ambient velocity of $2.1 \mathrm{~mm} / \mathrm{s}$ to the sink determined from Figure $7 \mathrm{a}$, having a strength of $0.0025 \mathrm{~m}^{3} / \mathrm{s}$. The vectors are horizontal and are in a plane $400 \mathrm{~mm}$ below the port. 
Author accepted version. Final publication as:

Davidson, M.J., Gaskin, S.J. \& Wood, I.R. (2002) A study of a buoyant axisymmetric jet in a small co-flow, Journal of Hydraulics Research, 40(4), pp 477- 489. doi.org/10.1080/00221680209499890

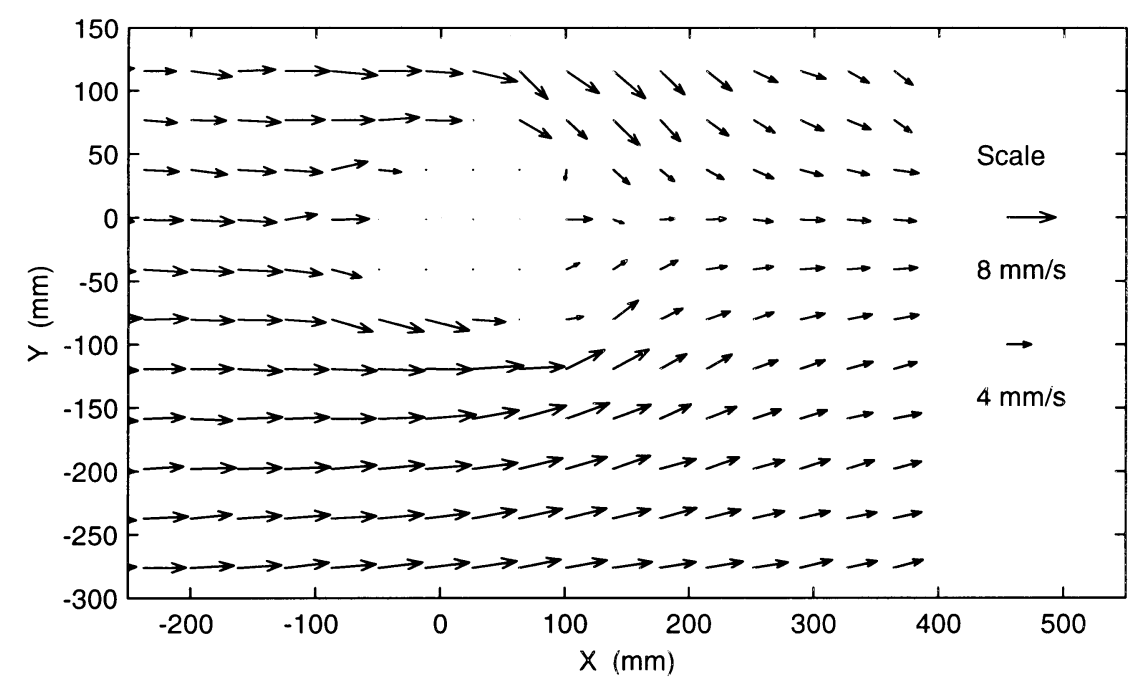

Figure 8a. The velocity vectors in the irrotational region for a buoyant jet ejected horizontally with a Froude number of 10 and a coflow of $6.1 \mathrm{~mm} / \mathrm{s}$. The vectors are horizontal and are measured in a plane $400 \mathrm{~mm}$ below the port. Using the measured velocities and subtracting the ambient velocity the sink strength was calculated as $0.004 \mathrm{~m}^{3} / \mathrm{s}$.

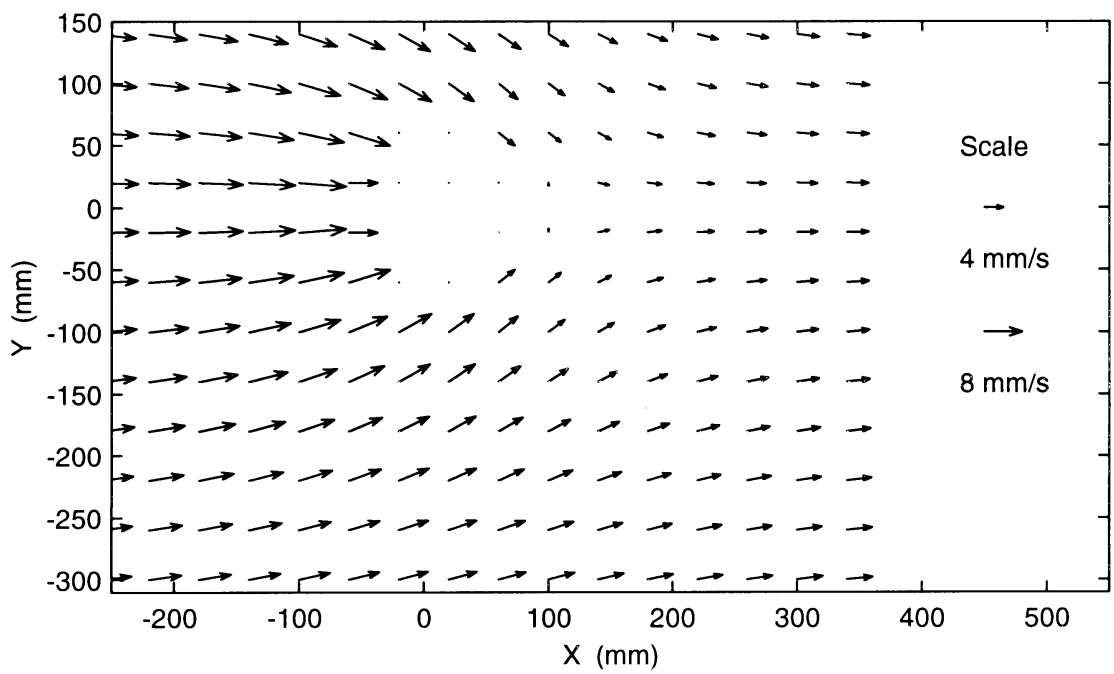

Figure $8 \mathrm{~b}$. The velocity vectors for a Froude number of 10 with a coflow of $6.1 \mathrm{~mm} / \mathrm{s}$. This is constructed by adding the coflow of $6.1 \mathrm{~mm} / \mathrm{s}$ to the sink determined from figure $8 \mathrm{a}$, having a strength of $0.004 \mathrm{~m}^{3} / \mathrm{s}$. The vectors are horizontal and are in a plane $400 \mathrm{~mm}$ below the port. 
Author accepted version. Final publication as:

Davidson, M.J., Gaskin, S.J. \& Wood, I.R. (2002) A study of a buoyant axisymmetric jet in a small co-flow, Journal of Hydraulics Research, 40(4), pp 477- 489. doi.org/10.1080/00221680209499890

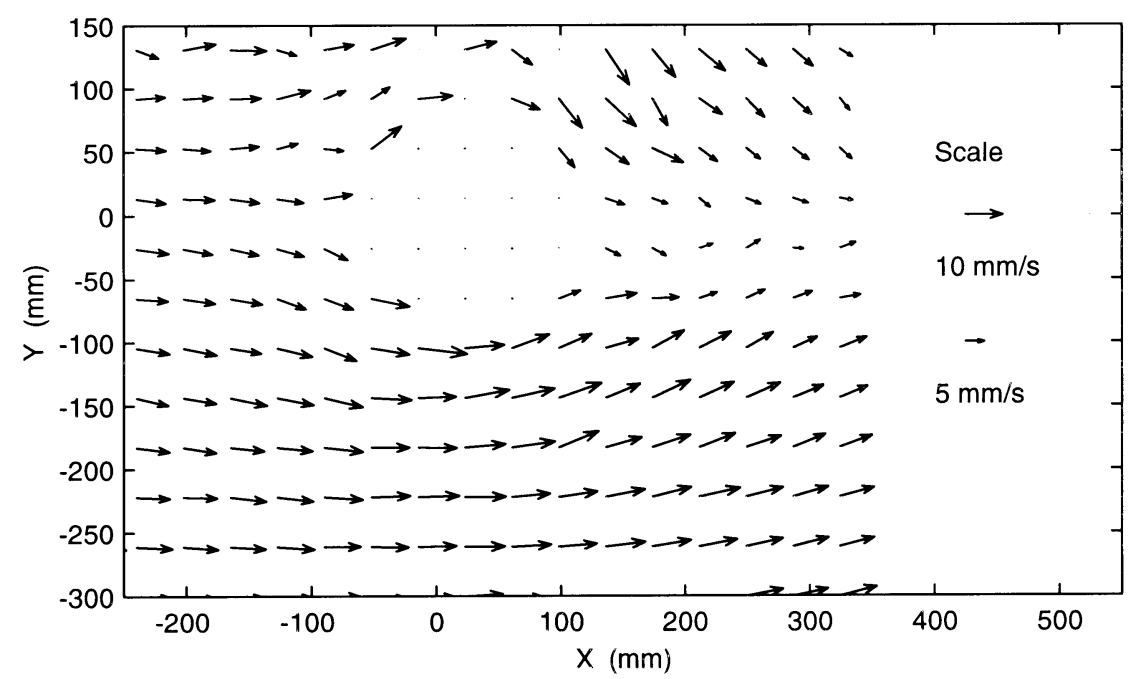

Figure 9a. The velocity vectors in the irrotational region for a buoyant jet ejected horizontally with a Froude number of 10 and a coflow of $11.2 \mathrm{~mm} / \mathrm{s}$. The vectors are horizontal and are measured in a plane $400 \mathrm{~mm}$ below the port. Using the measured velocities and subtracting the ambient velocity the sink value was calculated as $0.01 \mathrm{~m}^{3} / \mathrm{s}$.

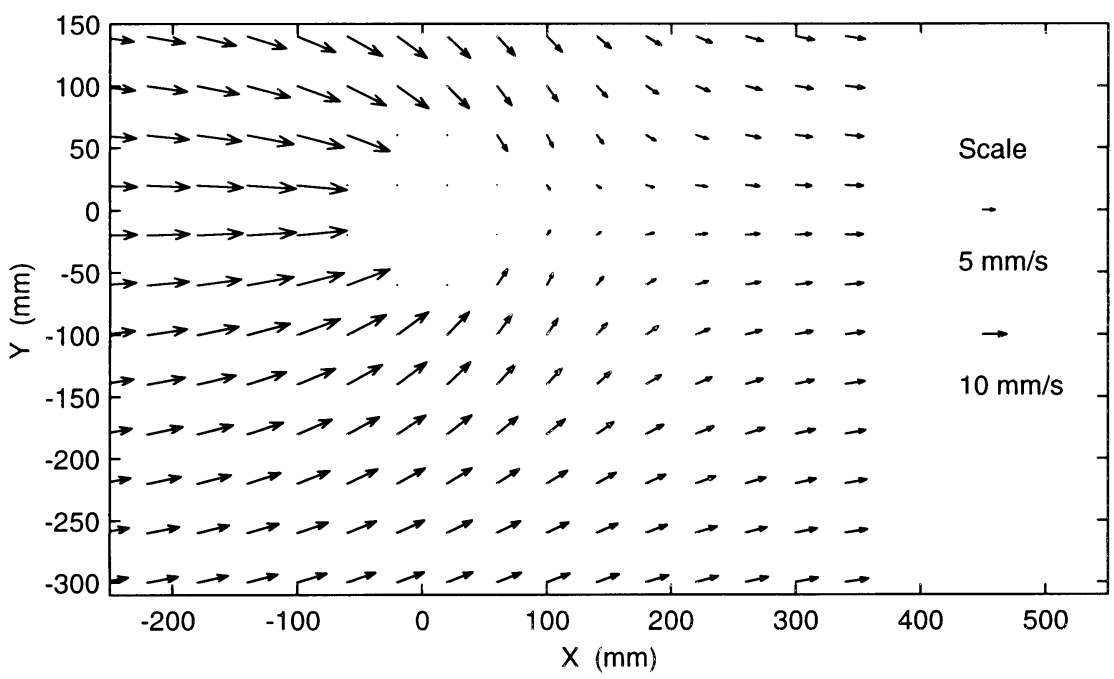

Figure $9 \mathrm{~b}$. The velocity vectors for a Froude number of 10 and coflow of $11.2 \mathrm{~mm} / \mathrm{s}$. This is constructed by adding the coflow of $11.2 \mathrm{~mm} / \mathrm{s}$ to the sink determined from figure $9 \mathrm{a}$, having a strength 0 $0.01 \mathrm{~m}^{3} / \mathrm{s}$. The vectors are horizontal and are in a plane $400 \mathrm{~mm}$ below the port. 
Author accepted version. Final publication as:

Davidson, M.J., Gaskin, S.J. \& Wood, I.R. (2002) A study of a buoyant axisymmetric jet in a small co-flow, Journal of Hydraulics Research, 40(4), pp 477- 489. doi.org/10.1080/00221680209499890

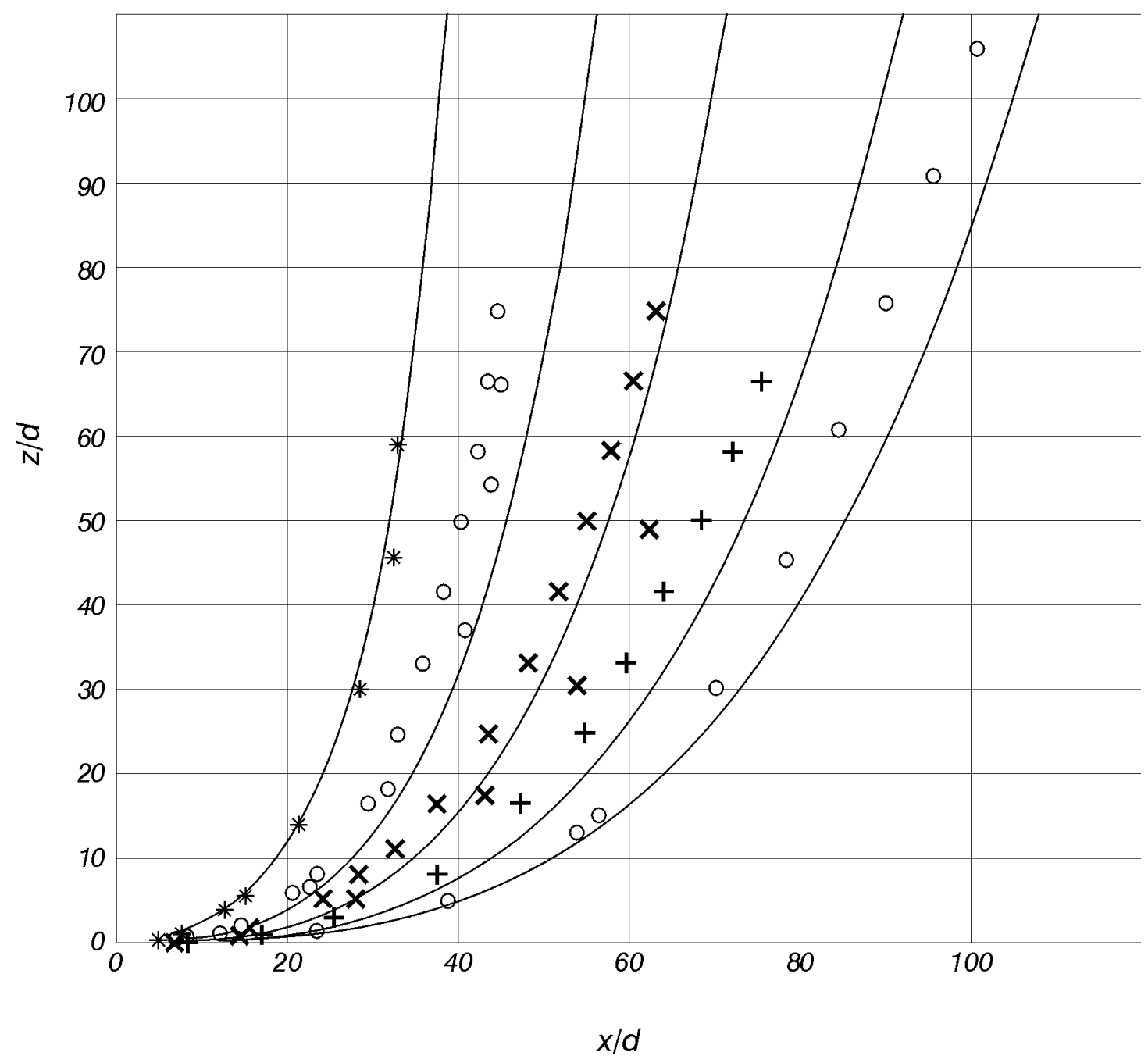

Figure 10. A comparison of the calculated trajectories for horizontally ejected plumes with experiments. The Froude numbers are 5, 10, 15, 20 and 25. (For the Froude number of 5 and 15 the experimental data from Davidson (1989) and Gaskin (1995) match. For the Froude of 10 there is some discrepancy and only the data from Davidson is plotted. Gaskins experiments did not extend to Froude numbers of 20 and 25.) 
Author accepted version. Final publication as:

Davidson, M.J., Gaskin, S.J. \& Wood, I.R. (2002) A study of a buoyant axisymmetric jet in a small co-flow, Journal of Hydraulics Research, 40(4), pp 477- 489. doi.org/10.1080/00221680209499890

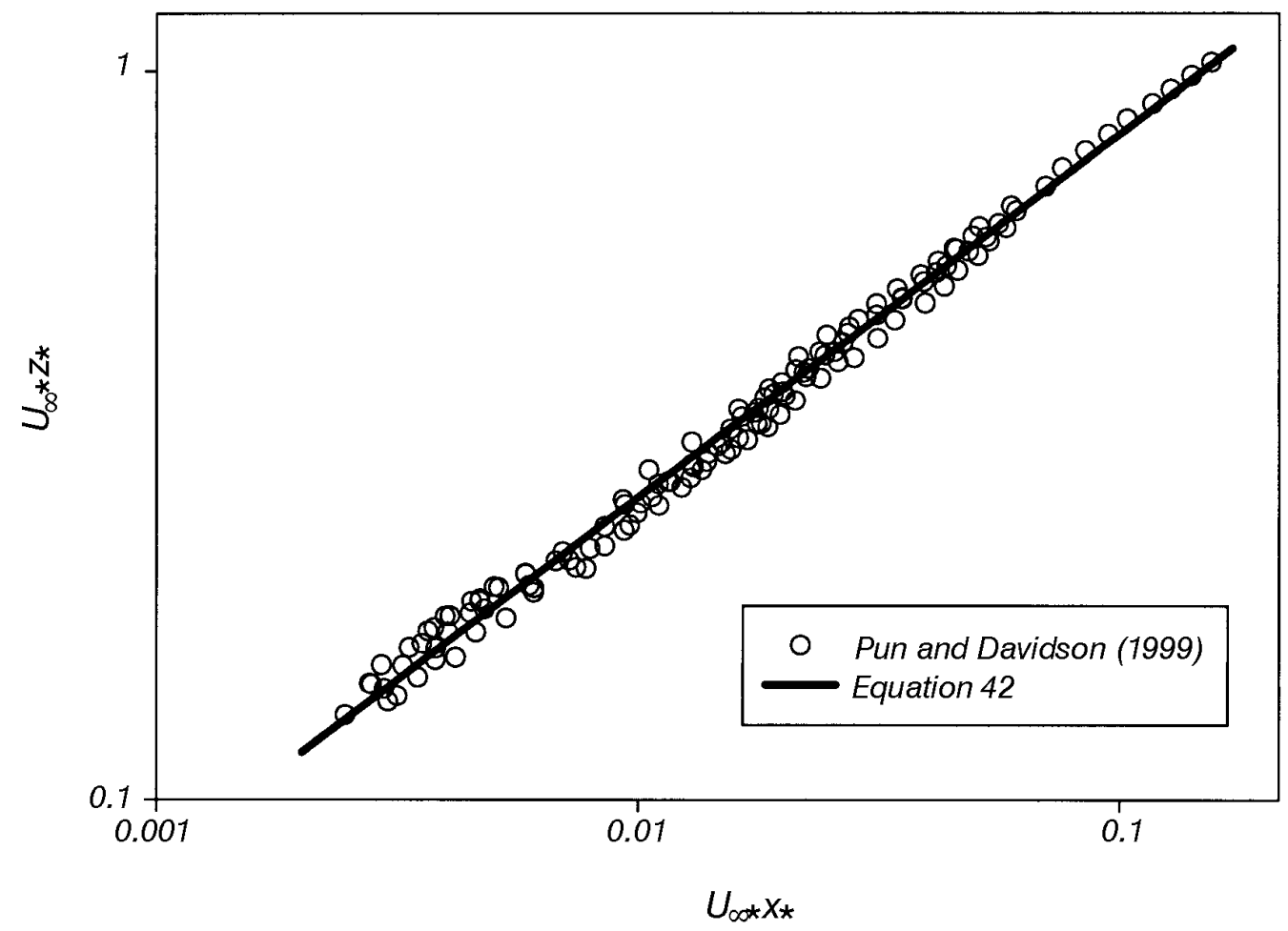

Figure 11. Trajectory data for an advected jet compared with theoretical predictions. 
Author accepted version. Final publication as:

Davidson, M.J., Gaskin, S.J. \& Wood, I.R. (2002) A study of a buoyant axisymmetric jet in a small co-flow, Journal of Hydraulics Research, 40(4), pp 477- 489. doi.org/10.1080/00221680209499890

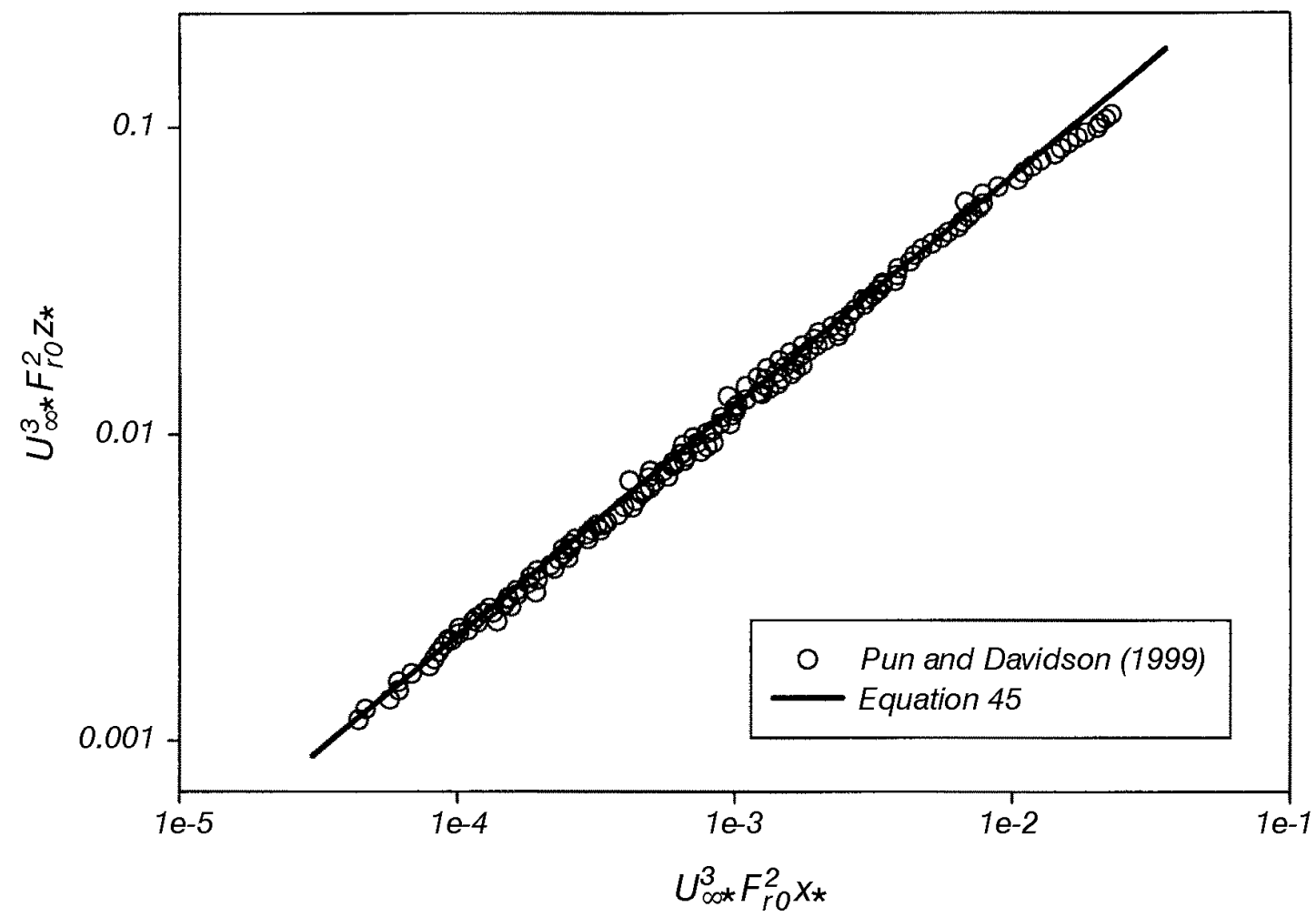

Figure 12. Trajectory data for an advected plume compared with theoretical predictions. 
Author accepted version. Final publication as:

Davidson, M.J., Gaskin, S.J. \& Wood, I.R. (2002) A study of a buoyant axisymmetric jet in a small co-flow, Journal of Hydraulics Research, 40(4), pp 477- 489. doi.org/10.1080/00221680209499890

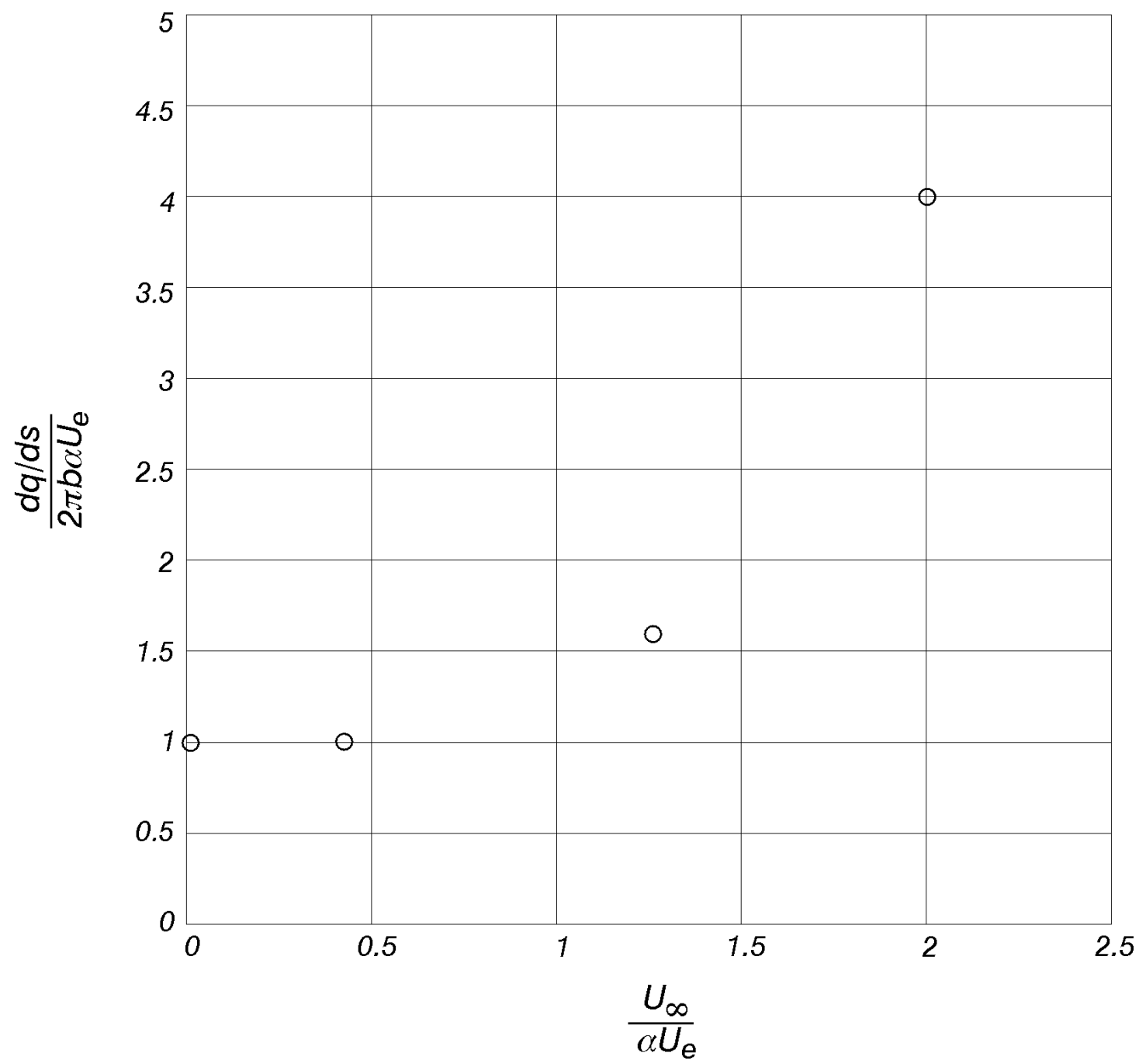

Figure 13. Direct measurements of the entrainment in advected horizontally discharged flows, divided by the entrainment with no ambient velocity. This non-dimensional entrainment is plotted against the component of the cross-flow velocity that is perpendicular to the turbulent flow, divided by the normal entrainment velocity. It should be noted that at this measuring position $\sin \theta \approx 1$. Data has been obtained for a Froude number of 10 with ambient velocities of of zero, $2.1 \mathrm{~mm} / \mathrm{s}, 6.1 \mathrm{~mm} / \mathrm{s}$ and $11.2 \mathrm{~mm} / \mathrm{s}$. 
Author accepted version. Final publication as:

Davidson, M.J., Gaskin, S.J. \& Wood, I.R. (2002) A study of a buoyant axisymmetric jet in a small co-flow, Journal of Hydraulics Research, 40(4), pp 477- 489. doi.org/10.1080/00221680209499890

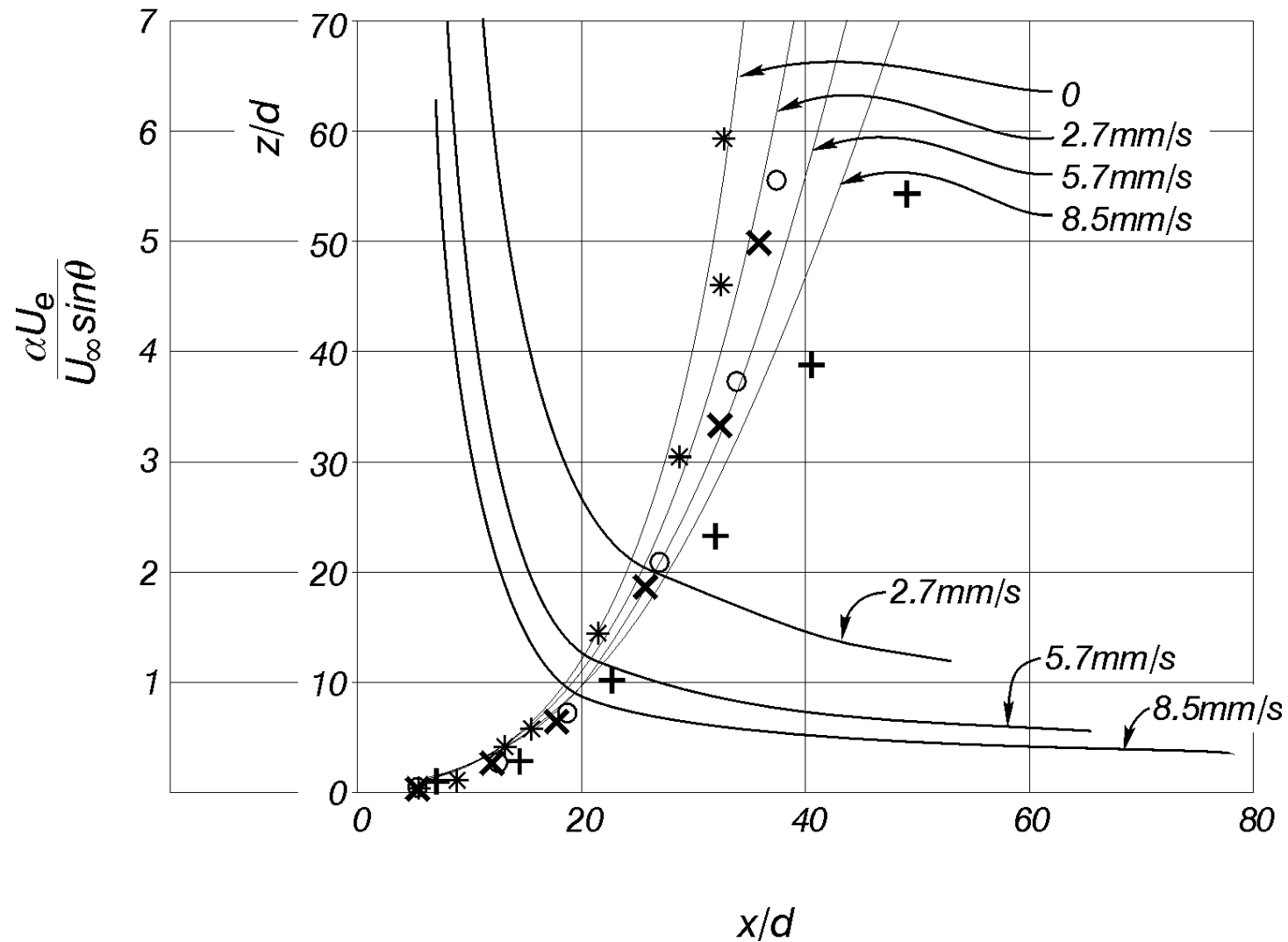

Figure 14. The trajectories for a horizontally ejected plume with a Froude number of 5 and ambient velocities of $0(*), 2.7(\mathrm{x}), 5.7(\mathrm{o})$ and $8.5 \mathrm{~mm} / \mathrm{s}(+)$ and the values of $\alpha U_{e} / U_{\infty} \sin \theta$ for the co-flow cases. It is notable that the trajectories with co-flows of $0,2.7$ and $5.7 \mathrm{~mm} / \mathrm{s}$ are with-in the experimental error. For the case of $8.5 \mathrm{~mm} / \mathrm{s}$ the entrainment constant required to fit the data is much greater than the constant for a jet or plume in stationary surroundings. This suggests that the critical value of $\alpha U_{e} / U_{\infty} \sin \theta$ is approximately one. 
Author accepted version. Final publication as:

Davidson, M.J., Gaskin, S.J. \& Wood, I.R. (2002) A study of a buoyant axisymmetric jet in a small co-flow, Journal of Hydraulics Research, 40(4), pp 477- 489. doi.org/10.1080/00221680209499890

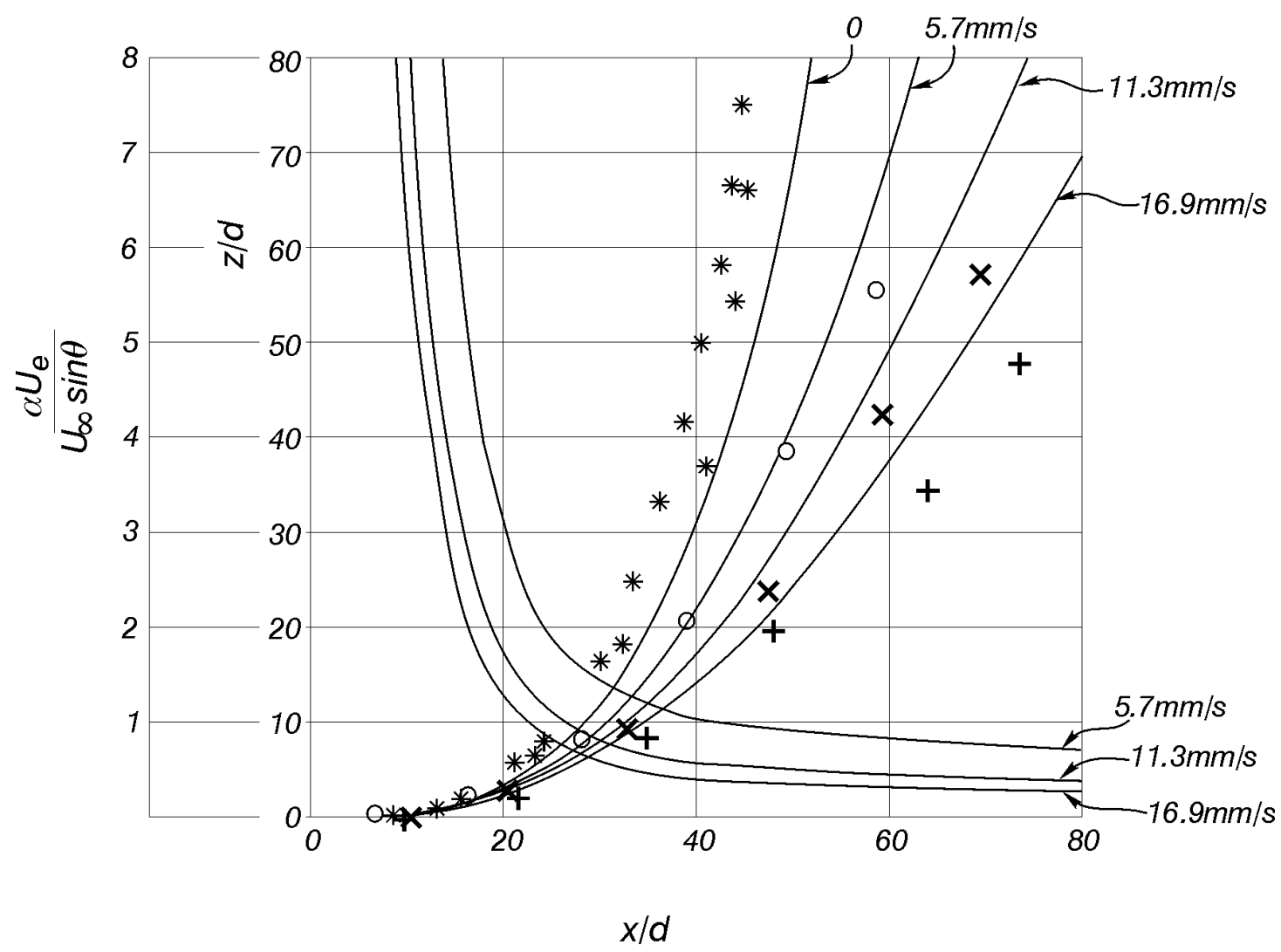

Figure 15. The trajectories for a horizontally ejected plume with a Froude number of 10 and co-flows of $0\left(^{*}\right)$, 5.7(o), $11.3(\mathrm{x})$ and $16.9 \mathrm{~mm} / \mathrm{s}(+)$ and the values of $\alpha U_{e} / U_{\alpha} \sin \theta$ for the co-flow cases. It is notable that the trajectories with co-flows of 0 and $5.7 \mathrm{~mm} / \mathrm{s}$ are with-in the experimental error. For the case of 11.5 and $16.9 \mathrm{~mm} / \mathrm{s}$ the entrainment constant required to fit the data is much greater than the constant for a jet or plume in stationary surroundings. Again this suggests that the critical value of $\alpha U_{e} / U_{\infty} \sin \theta$ is approximately one. 
Author accepted version. Final publication as:

Davidson, M.J., Gaskin, S.J. \& Wood, I.R. (2002) A study of a buoyant axisymmetric jet in a small co-flow, Journal of Hydraulics Research, 40(4), pp 477- 489. doi.org/10.1080/00221680209499890

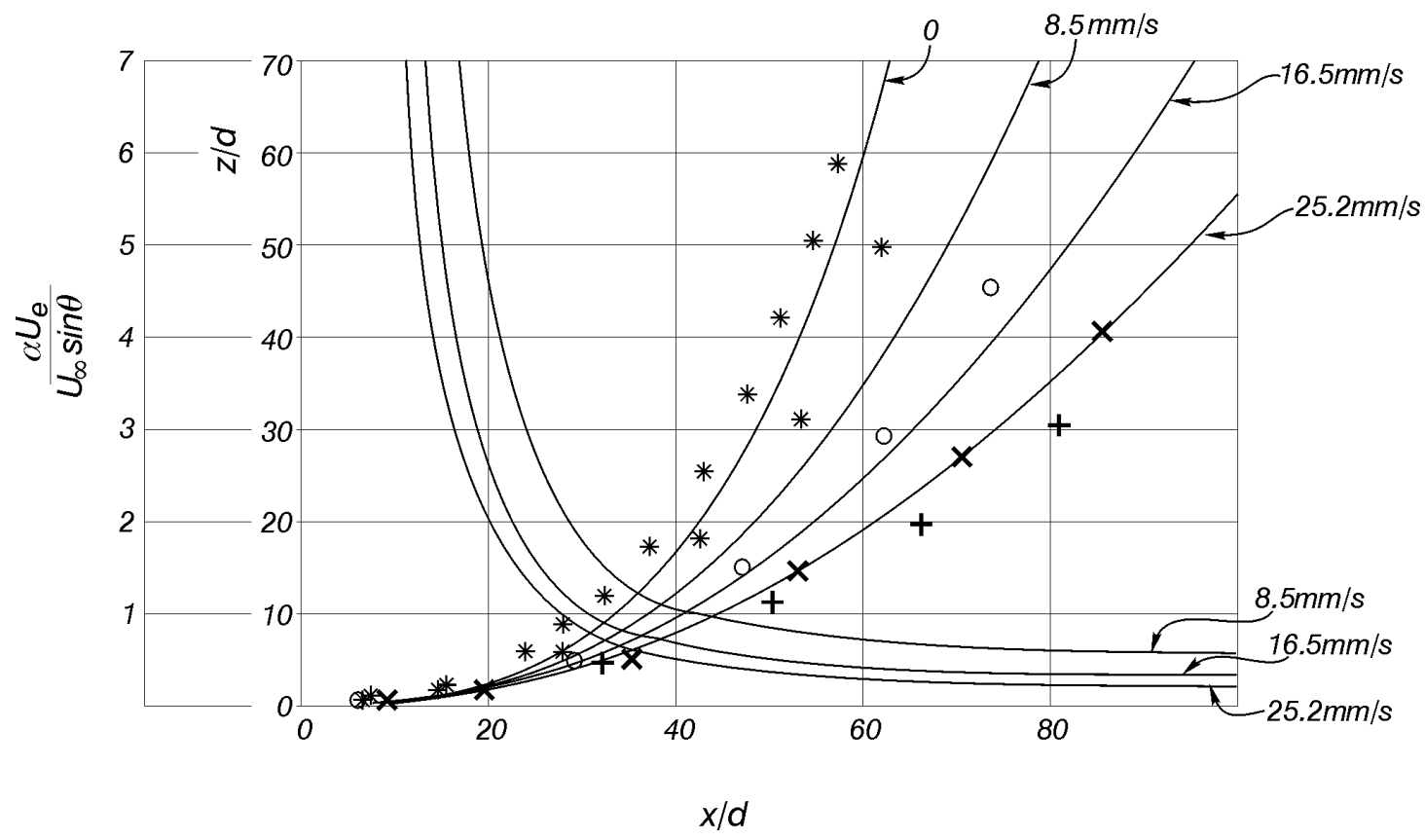

Figure 16. The trajectories for a horizontally ejected plume with a Froude number of 15 and co-flows of $0(*)$, 8.5(o), $16.5(\mathrm{x})$ and $25.2 \mathrm{~mm} / \mathrm{s}(+)$ and the values of $\alpha U_{e} / U_{\alpha} \sin \theta$ for the co-flow cases. All the co-flow cases depart from the theory. 